\title{
EFEITOS DO ALUMÍNIO E MECANISMOS DE TOLERÂNCIA À TOXICIDADE EM ESPÉCIES DE Eucalyptus E Pinus
}

\author{
SIMONE DA SILVA GoMeS \\ Engenheiro Florestal \\ Orientador: Prof. Dr. JOSÉ LEONARDO DE M. GONÇALVES \\ Dissertação apresentada à Escola Superior de \\ Agricultura "Luiz de Queiroz", Universidade de São \\ Paulo, para obtenção do titulo de Mestre em \\ Agronomia, Área de concentração: Solos e Nutrição \\ de Plantas.
}

P I R A C I C A B A

Estado de São Paulo - Brasil

Maio - 2001 


\title{
Dados Internacionais de Catalogação na Publicação (CIP) DIVISÃO DE BIBLIOTECA E DOCUMENTAÇÃO - CampuS "Luiz de Queiroz"/USP
}

\author{
Gomes, Simone da Silva \\ Efeitos do aluminio e mecanismos de tolerância à toxicidade em espécies de
} Eucalyptus e Pinus/ Simone da Silva Gomes. - - Piracicaba, 2001.

$39 \mathrm{p}$.

Dissertação (mestrado) - Escola Superior de Agricultura Luiz de Queiroz, 2001. Bibliografia.

1. Crescimento vegetal 2. Eucalipto 3. Nutrição vegetal 4. Pinheiro 5. Tolerância ao alumínio 6. Toxicidade I. Título

CDD 634.9734

Termitida a copia total ou parcial deste documento. desde que citada a fonte $=0$ autor" 
A Deus,

Ofereço.

Aos meus pais Ivo e Maria,

Pelo apoio, pelo incentivo, pelo amor e pela formação pessoal e profissional que permitiram -me desenvolver este trabalho,

Ao meu querido esposo Fernando e ao meu pequeno filho Pedro Fernando,

Pela compreensão, pelo estímulo e pelo carinho dedicado durante toda a execução deste trabalho,

Dedico. 


\section{AGRADECIMENTOS}

Aos meus pais, meu esposo e ao meu pequeno filho..., por tudo.

Ao Prof. José Leonardo de M. Gonçalves, pela oportunidade do ingresso no curso de Pós Graduação, por trabalharmos juntos, pela orientação, ensinamentos, amizade, confiança e aprimoramento técnico-científico.

Ao Departamento de Solos e Nutrição de Plantas, pela oportunidade do ingresso no curso de Pós Graduação.

Às minhas grandes amigas Engenheira Florestal Adriana S. Silva e Engenheira Agrônoma Márcia Toffani, pelas sugestões na pesquisa, pelo carinho e principalmente pela amizade.

A equipe do Laboratório de Ecologia Aplicada (Juliana, Francismara, Luciana, Fernanda e Alba), pela excelente colaboração.

A equipe do Viveiro Florestal: Amarildo, Luciane, Ivan, José Benedito, José Francisco e todos que direta ou indiretamente me ajudaram, obrigado por tudo.

Aos inúmeros colegas de pós-graduação e graduação, professores e funcionários da UNESP, UNICAMP, ESALQ e amigos de Piracicaba, que colaboraram direta ou indiretamente na realização do trabalho.

A ESALQ, por facilitarem a pesquisa (biblioteca, internet e laboratórios) e a CAPES pela bolsa de Mestrado, que muito facilitaram minha manutenção e meus estudos. 


\section{SUMÁRIO}

Página

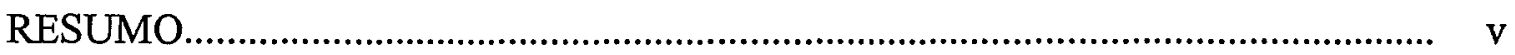

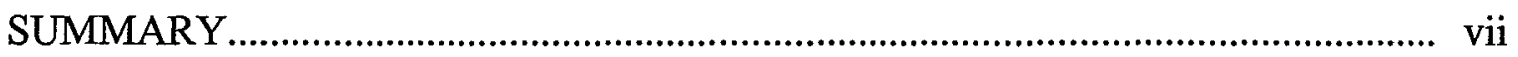

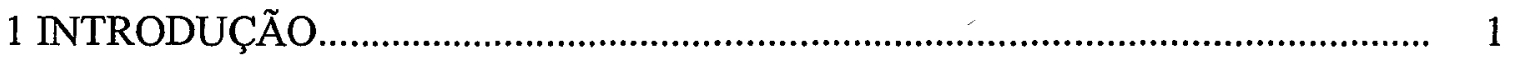

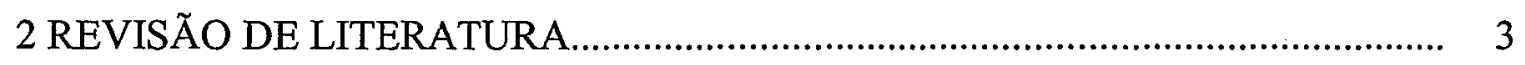

2.1 Mecanismos de Tolerância ao alumínio ............................................................. 8

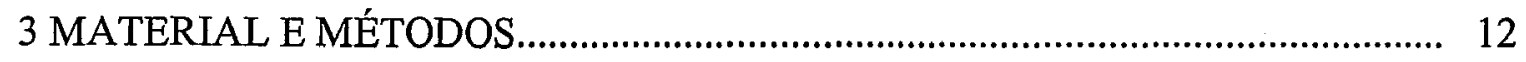

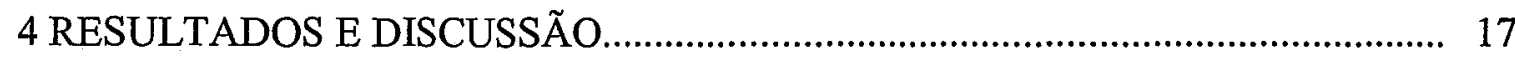

4.1 Efeito do alumínio sobre o crescimento da planta............................................... 17

4.2 Composição e acúmulo de nutrientes nos diferentes componentes das mudas....... 22

4.3 Capacidade de troca de cátions de raízes finas.......................................................... 27

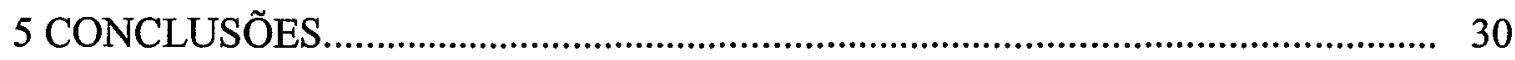

REFERÊNCIAS BIBLIOGRÁFICAS.......................................................... 31 


\title{
EFEITOS DO ALUMÍNIO E MECANISMOS DE TOLERÂNCIA À TOXICIDADE EM ESPÉCIES DE Eucalyptus E Pinus
}

\author{
Autora: SIMONE DA SILVA GOMES
}

\section{Orientador: Prof. Dr. JOSÉ LEONARDO DE M. GONÇALVES}

\section{RESUMO}

O objetivo deste trabalho foi avaliar o efeito do alumínio na parte aérea e sistema radicular de mudas de três espécies de Eucalyptus (E. grandis, E. urophylla e o híbrido $E$. grandis vs. E. urophylla) e duas espécies de Pinus ( $P$. oocarpa e $P$. caribaea var. hondurensis), consideradas tolerantes ao alumínio. Foram consideradas como hipóteses: a) quanto maior o teor de alumínio no solo maiores as alterações na morfologia radicular; b) quanto maior a CTC de raiz maior a adsorção e absorção de alumínio. $\mathrm{O}$ experimento foi conduzido durante o período de março de 2000 a janeiro de 2001, em de casa de vegetação. Foram utilizadas amostras de terra da camada de 0 a $20 \mathrm{~cm}$ de profundidade de um solo caracterizado como Latossolo Vermelho A moderado distrófico textura média (240 $\mathrm{g} \mathrm{kg}^{-1}$ de argila), originário da região de cerrado. Os atributos químicos das amostras originais foram: $\mathrm{pH} \mathrm{em} \mathrm{CaCl}_{2}=3,9 ; \mathrm{MO}=28 \mathrm{~g} \mathrm{dm}^{-3}$; P-resina $=5 \mathrm{mg} \mathrm{dm}{ }^{-3} ; \mathrm{Ca}=0,4 \mathrm{e} \mathrm{Al}=15 \mathrm{mmol}_{\mathrm{c}} \mathrm{dm}^{-3}$. Os tratamentos foram os seguintes: 1) adubação básica - $50 \mathrm{mg}$ de $\mathrm{N}, 100 \mathrm{mg}$ de $\mathrm{K}, 250 \mathrm{mg}$ de $\mathrm{P}$ e $45 \mathrm{mg}$ de $\mathrm{S}$ $\mathrm{kg}^{-1}$ de solo; 2) adubação básica mais $\mathrm{CaCO}_{3}$ e $\mathrm{MgCO}_{3}$, na relação estequiométrica de $4: 1$; 3) adubação básica mais $\mathrm{CaSO}_{4}$ e $\mathrm{MgCl}_{2}$; e 4) adubação básica com aplicação de $125 \mathrm{mg} \mathrm{P} \mathrm{kg}{ }^{-1}$ de solo mais $\mathrm{CaSO}_{4}$ e $\mathrm{MgCl}_{2}$. Nos tratamentos 2, 3 e 4, estimou-se quantidades de reagentes suficientes para elevar o teor de $\mathrm{Ca}+\mathrm{Mg}$ para $10 \mathrm{mmol}_{\mathrm{c}} \mathrm{kg}^{-1}$ 
de solo. Após aplicação dos tratamentos, as amostras de terra foram acondicionadas em vasos de polietileno com capacidade para $4 \mathrm{~kg}$, onde foram semeadas e mantidas duas plantas de cada espécie até a colheita. As plantas de Eucalyptus foram colhidas com 210 dias e, as de Pinus, com 300 dias. As respostas das plantas aos tratamentos foram estimadas medindo-se a altura, o diâmetro do colo e a produção de matéria seca da parte aérea e sistema radicular das mudas. Em todo material colhido foram feitas determinações das concentrações de macro, micronutrientes e alumínio. Para todas as espécies, as raízes foram separadas em duas classes: a) raízes com diâmetro $\leq 1 \mathrm{~mm}$ e b) raízes com diâmetro entre 1 e $3 \mathrm{~mm}$. $\mathrm{O}$ comprimento radicular foi estimado digitalmente pelo sistema SIARCS (Sistema Integrado para Análise de Raízes e Cobertura do Solo). A capacidade de troca de cátions das raízes finas com diâmetro $\leq 1 \mathrm{~mm}$ foi estimada por meio da saturação-remoção da $\mathrm{CTC}$ das raízes com íons $\mathrm{H}^{+}$e posterior titulação destes íons. As Espécies de Eucalyptus e de Pinus não apresentaram diferenças de crescimento em altura, diâmetro do colo e produção de matéria seca da parte aérea entre os diferentes níveis de saturação de alumínio e disponibilidade de nutrientes no solo. Maior densidade de raízes finas foram encontradas nos tratamentos com menores teores de bases e maiores teores de alumínio no solo, para todas as espécies estudadas. A CTC de raiz das espécies de Pinus foi maior do que as de Eucalyptus, as quais apresentaram menor teor foliar de alumínio. Os teores de alumínio nas raízes finas foram muito maiores do que as encontradas nos tecidos foliares. nas espécies de Pinus as diferenças foram maiores. 


\title{
EFFECTS OF ALUMINUM AND TOXICITY TOLERANCE MECHANISMS IN EUCALYPT AND PINE SPECIES
}

\author{
Author: SIMONE DA SILVA GOMES
}

\section{Adviser: Prof. Dr. JOSÉ LEONARDO DE M. GONÇALVES}

\section{SUMMARY}

The aim of this research was to evaluate the effects of aluminum on seedlings of eucalyptus (E. grandis, E. urophylla and hybrid E.. grandis vs. E. urophylla) and pine ( $P$. oocarpa and $P$. caribaea var. hondurensis), considered aluminum-tolerant. Two hypothesis were considered: a) the higher the aluminum content in the soil the higher were the morphological changes of the roots; $b$ ) the higher the root CTC the higher was the aluminum adsorption and absorption. The experiment was conducted in a glasshouse from March 2000 to January 2001 using samples of a medium-textured alic Dark-Red Latosol. Samples of 0 to $20-\mathrm{cm}$ depth of earth of a medium-textured dystrophic moderate $\left(240 \mathrm{~g} \mathrm{~kg}^{-}\right.$ ${ }^{1}$ clay) Red A Latosol were used. The chemical attributes of the original samples were $\mathrm{pH}$ in $\mathrm{MgCl}_{2}=3.9 ; \mathrm{MO}=28 \mathrm{~g} \mathrm{dm}^{-1} ; \mathrm{P}-\mathrm{resin}=5 \mathrm{mg} \mathrm{dm}^{-3} ; \mathrm{Ca}=0.4$ and $\mathrm{Al}=15 \mathrm{mmol}_{\mathrm{c}} \mathrm{dm}^{-3}$. The treatments consisted of basic fertilization $-50 \mathrm{mg} \mathrm{N}, 100 \mathrm{mg}$ of $\mathrm{K}, 250 \mathrm{mg}$ of $\mathrm{P}$ and $45 \mathrm{mg}$ of $\mathrm{S} \mathrm{kg}^{-1}$ of soil before planting; basic fertilization plus $\mathrm{CaCo}_{3}$ and $\mathrm{MgCo}_{3}$; basic fertilization plus $\mathrm{CaSO}_{4} \mathrm{e} \mathrm{MgCl}_{2}$; and basic fertilization with $125 \mathrm{mg}$ of $\mathrm{P} \mathrm{kg}^{-1}$ of soil plus $\mathrm{CaSO}_{4}$ and $\mathrm{MgCl}_{2}$. The amounts of reagents, enough to raise the $\mathrm{Ca}+\mathrm{Mg}$ content for 10 $\mathrm{mmol}_{\mathrm{c}} \mathrm{kg}^{-1}$ of soil, were estimated in treatments 2,3 and 4. After the application of treatments the earth samples were placed in 4-kg polyethylene pots with two plants of each species planted until harvest. The Eucalyptus and Pinus plants were collected 210 and 300 days after seeding, respectively. The plant responses to the treatments were estimated through the height, colon diameter and dry matter production of the aerial part and root 
system of the seedlings. Aluminum macro and micro nutrient concentrations were determined. For all species, the roots were separated in two classes: a) roots with diameter $\leq 1 \mathrm{~m}$ and $\mathrm{b}$ ) roots with diameter between 1 and $3 \mathrm{~mm}$. The root length was digitally estimated by the SIARCS system (Integrated System for the Analysis of Roots and Soil Cover). The cation exchange capacity of fine roots with diameter $\leq 1 \mathrm{~mm}$ was estimated by saturating-removing root $\mathrm{CTC}$ with $\mathrm{H}+$ ions and further titration of the ions. The eucalyptus and pine did not present differences regarding height, colon diameter and dry matter production of the aerial part among the different levels of aluminum saturation and soil nutrient availability. A higher dry matter density of fine roots was verified in the treatments with lower availability of bases and higher aluminum content in the soil for all species studied. The cation exchange capacity of pine roots was higher than that of the Eucalyptus, which had a lesser aluminum leaf content. The aluminum contents in fine roots were much higher than those found in leaf tissues. In Pinus species the differences were more evident. 


\section{INTRODUÇÃo}

A toxicidade do alumínio é um dos fatores mais limitantes à produtividade das culturas em solos ácidos, os quais compreendem $51 \%$ dos solos tropicais (Sanches \& Salinas,1981). De modo geral, o efeito tóxico do alumínio na planta tem sido associado a uma redução no desenvolvimento e funcionamento do sistema radicular; nessas condições as raízes exploram menor volume de solo, em conseqüência, as plantas sensíveis apresentam baixa eficiência na absorção de nutriente e alta suscetibilidade à seca. Várias espécies de Eucalyptus são consideradas tolerantes à toxicidade de alumínio apresentando bons índices de produtividade em solos ácidos e álicos, não respondendo à correção do $\mathrm{pH}$ por meio da calagem (Barros \& Novais, 1990). Contudo, pouco se conhece sobre os mecanismos de tolerância ao alumínio por estas espécies, bem como para várias espécies de Pinus tidas como tolerantes à toxicidade de alumínio.

Vários estudos apresentam fortes evidências de que, pelo menos, parte dos mecanismos de tolerância à toxicidade por alumínio estejam nas raízes (Neves et al., 1982; Braccini et al.,1998). Segundo Novais et al.(1980), Furlani (1989) e Barros et al. (1990), essa tolerância varia em função da espécie e, para uma mesma espécie, varia em função da variedade e do estado fisiológico, provavelmente, por não haver um único mecanismo de tolerância.

Alguns pesquisadores (Nambiar et al., 1982; Gonçalves \& Mello, 2000), em ampla revisão bibliográfica, destacaram a importância da configuração e função radicular nas práticas de manejo de plantações florestais e nos programas de melhoramento florestal, em especial, com relação à adaptação às condições adversas de clima e de solo. Segundo estes pesquisadores, a maioria das espécies florestais 
apresentam grande variação genética e alta herdabilidade, quanto aos atributos do sistema radicular, podendo ser trabalhadas geneticamente no sentido de produzir plantas mais tolerantes às adversidades ambientais.

O objetivo deste trabalho foi avaliar o efeito do alumínio na parte aérea e sistema radicular de mudas de três espécies de Eucalyptus (E. grandis, E. urophylla e o híbrido $E$. grandis vs. E. urophylla) e duas espécies de Pinus ( $P$. oocarpa e $P$. caribaea var. hondurensis), consideradas tolerantes ao alumínio. Foram consideradas como hipóteses: a) quanto maior o teor de alumínio no solo maiores as alterações na morfologia radicular; b) quanto maior a CTC de raiz maior a adsorção e absorção de alumínio. 


\section{REVISÃO DE LITERATURA}

Um dos primeiros sintomas visíveis da fitotoxicidade em plantas cultivadas em substrato solo ou solução nutritiva contendo alumínio em excesso, consiste de graves anomalias nas raízes (Camargo \& Furlani,1989; Malavolta et. al., 2000).

Segundo Taylor (1988), a afirmativa de que as ações tóxicas do alumínio trocável nas plantas relacionam-se às raízes, decorrem de duas linhas de evidências: a variação na produção de fitomassa radicular é mais sensível ao alumínio que a variação de produção de fitomassa de órgãos da parte aérea, ou seja, as reduções nas taxas de crescimento de raízes são os primeiros sintomas observáveis da fitotoxidez de alumínio, e; devido à ausência de universalidade na correlação entre o suprimento de alumínio e seu respectivo acúmulo, na parte aérea.

De acordo com Malavolta (1980), o meristema apical das raizes é provavelmente o sítio inicial da ação tóxica do alumínio. As células da coifa tornam-se vacuoladas com a interrupção da função do aparelho de Golgi e do desenvolvimento de plastídeos, ocorrendo alterações na estrutura nuclear, perda de citoplasma e a desintegração. As células epidérmicas, endodérmicas e corticais se autolisam, tornando-se inchadas e desorganizadas, as regiões meristemáticas das raízes primárias e laterais se desorganizam a ponto de dificultar a distinção entre coifa e elementos vasculares. Ocorre

deformação da parede celular e um número elevado de células binucleadas, devido à redução da atividade mitótica.

Segundo alguns pesquisadores (Furlani, 1989; Malavolta et al., 1989; Foy, 1992; Baligar et al., 1993), o excesso de alumínio trocável inibe o crescimento normal das 
raízes, tornando-as grossas, com coloração marrom, ocasionalmente com manchas necróticas, quebradiças, aparência coralóide, desprovidos de raízes finas, com poucas ramificações laterais e inibição da elongação do eixo principal. Como consequiência, o sistema radicular é pouco desenvolvido, estabelecendo um aumento na produção da matéria seca de raiz por unidade de nutriente absorvido (Taylor,1988).

O alumínio também afeta os carregadores da membrana, inibindo as atividades das enzimas ATPase, ligando-se tantos aos lipídios como às proteínas, alterando a enzima pela modificação nas interações lipídeos-proteínas, ou pode atuar diretamente na proteína enzimática ou em proteínas envolvidas na estimulação da enzima, conforme ocorre com a atividade da calmodulina-Ca, que exerce papel importante na manutenção do potencial de membrana. Esse efeito ocasiona alterações da integridade estrutural e da permeabilidade das membranas, podendo promover o efluxo de íons (Reis \& Kimmins, 1986; Marschner, 1986; Huang \& Bachelard, 1993).

$\mathrm{Na}$ célula da planta, o alumínio pode interferir no metabolismo do fósforo pela formação de complexos estáveis de Al-P, além de afetar as atividades das enzimas fosfoquinases e ATP-ases, e de funcionar como agente fortemente complexador dos fosfato e ácidos nucléicos, resultando na interferência em reações energéticas, na inibição da divisão celular; e, na absorção e no transporte de nutriente na planta (Baligar et al., 1993; Foy, 1992; Neves et al., 1982; Roy et al., 1988; Mengel \& Kirkby ,1982).

, Foy (1984) verificou que em $\mathrm{pH}$ menores que 5.5, o antagonismo entre $\mathrm{Al}$ x Ca é provavelmente o fator mais limitante na absorção do cálcio e a toxicidade de alumínio pode se manifestar como uma deficiência de cálcio induzida, estabelecendo um colapso nos pontos de crescimento ou nos pecíolos, em conseqüência, de uma redução na absorção e na translocação de cálcio na planta, principalmente como resultado do bloqueio ou competição nos sítios de troca na raiz (Marschner, 1986; Bueno, 1987).

- A fitotoxidez de alumínio pode ser atribuída diretamente a uma deficiência de fósforo induzida por este íon, devido a uma reação de precipitações de fosfato de alumínio, tanto na solução externa às raízes como no espaço livre aparente, reduzindo sua absorção pelas raízes, e o seu subsequente transporte para a parte aérea (Bassioni, 
1973; Adams, 1980; Malavolta, 1980; Foy, 1988; Braccini et al.,1998). Segundo MacKlon \& Sim (1992), a maior parte do alumínio absorvido pelas raízes liga-se a sítios de adsorsão na parede celular e sobre esta superficie o fosfato se precipita, impedindo a movimentação do fósforo nos tecidos radiculares.

Segundo Camargo (1985), há uma maior redução na eficiência de utilização do fósforo no sistema radicular que na parte aérea, possivelmente em função de maior acúmulo de fósforo na raiz. De acordo com Adams (1984), pode ocorrer uma precipitação de fosfato de alumínio tanto nos tecidos radiculares, como na parte aérea, pois nem todo o alumínio absorvido torna-se adsorvido e/ou precipitado nas raízes. Bueno (1987) estudando a nutrição mineral de espécies de seringueira, verificou que com um aumento na concentração de alumínio na solução nutritiva ocorreu um decréscimo nas concentrações de fósforo nas raízes, no caule e nas folhas do verticilio inferior, sendo indícios de precipitações de fosfato de alumínio nestes compartimentos.

A toxicidade do alumínio nas raízes pode também exercem efeito sobre o balanço hormonal, reduzindo a síntese e o transporte de citocinina nos meristemas das raízes, alterando a direção do movimento da auxinas, favorecendo o transporte acrópeto ao invés do basípeto, e aumenta os níveis de ácido abscísico (Haug, 1984). Braccini et al. (1998) observaram no sistema radicular de cafeeiro que um dos sintomas da toxicidade ao alumínio manifestou-se pelo aumento do número de raízes laterais, avaliado a partir de amostras de $15 \mathrm{~cm}$ apicais da raiz. Tendo como hipótese, de que o efeito tóxico do alumínio na destruição das células da região meristemática da raiz principal tenha alterado a produção de hormônios que controlam o crescimento de raízes laterais e, a perda da dominância apical manifestou-se pela proliferação de raízes laterais.

Em condições de campo, as reduções na capacidade de exploração de água e nutrientes podem estar relacionadas à atuação de efeitos isolados ou em conjunto de diversos fatores, como menor volume de solo explorado e/ou inibição na absorção de nutrientes, em função de bloqueio ou competição nos sítios de troca na raiz (Camargo \& Furlani,1989). 
A hipótese de que o alumínio em baixas concentrações pode favorecer o crescimento e a produção, bem como proporcionar efeitos favoráveis em espécies tolerantes, como estimular a absorção de nutrientes, foi verificada por alguns autores (Minotti et al.,1969; JacKson et al., 1977; Bueno, 1987; Novais et al., 1990).

Foy (1974) relacionou as seguintes hipóteses para esse mecanismo: 1) aumento na disponibilidade do ferro (através da hidrólise do alumínio e da diminuição do $\mathrm{pH}$ ); 2) correção ou prevenção de deficiência de ferro, pela liberação do ferro adsorvido em sítios metabolicamente inativos dentro da planta; 3) bloqueio dos sítios, da parede celular, carregado negativamente, promovendo a absorção do fósforo; 4) retardamento da deterioração das raízes em baixas concentrações de cálcio pelo crescimento mais lento; 5) prevenção de toxicidade de cobre e manganês.

De encontro com estas explicações Grime \& Rodgson (1969) verificaram efeitos benéficos do alumínio no crescimento da espécie Scabiosa columbrera, devido à melhor utilização do ferro, resultante da substituição deste elemento pelo alumínio nos sítios de troca da raiz.

Neves et al.(1982) observou em espécies de eucalipto valores da relação matéria seca da parte aérea/matéria seca das raízes menores em tratamentos com maiores concentrações de alumínio trocável. Verificou que além do maior crescimento da planta como um todo, ocorreu um maior equilíbrio entre o crescimento dessas duas partes da planta, sugerindo ter havido uma distribuição mais equilibrada de fotoassimilados entre parte aérea e raízes, além de ter elevado a eficiência de absorção de nitrato, em razão da redução da permeabilidade da plasmalema ao $\mathrm{N}^{-\mathrm{NO}_{3}}{ }^{-}$, provavelmente pelo o alumínio substituir o cálcio no papel estrutural ou funcional e reduzir a permeabilidade da membrana plasmática ao $\mathrm{N}-\mathrm{NO}_{3}{ }^{-}$, e por reduzir a restrição imposta à difusão $\mathrm{NO}_{3}{ }^{-}$pelas cargas negativas no ELA, propiciando maior acesso do $\mathrm{NO}_{3}{ }^{-}$aos sítios de absorção ativa.

Segundo Andrew \& Berg (1973), algumas leguminosas tropicais mais tolerantes ao alumínio, apresentam maior absorção de fósforo, quando o alumínio esta presente em baixas concentrações. De acordo com Mullette \& Hannon (1974), em concentrações elevadas de alumínio, ocorre supersaturação dos sítios negativos, com precipitação de 
alumínio ligado a fósforo e, em baixas concentrações, o alumínio bloqueia os sítios negativamente carregados da parede celular, facilitando a absorção, principalmente, de fósforo e nitrato.

Huang \& Bachelard (1993) avaliaram o comportamento das espécies de eucalipto e pinus, em soluções nutritivas contento alumínio. Observaram que com o aumento da concentração de alumínio na solução nutritiva, houve maior crescimento em ambas espécies: o eucalipto cresceu em até $2220,0 \mathrm{mmol} \mathrm{L}^{-1}$ de alumínio; o pinus teve maior crescimento em $370 \mathrm{mmol} \mathrm{L}^{-1}$ de alumínio; na ausência de $\mathrm{Al}$ o pinus apresentou o menor crescimento, indicando que em baixas concentrações o alumínio pode ser um elemento essencial ou intensificar a ação de outro fator de crescimento em espécies de pinus.

Do mesmo modo, Bueno (1987) observou que a presença do alumínio estimulou o crescimento em altura e a produção de matéria seca para a espécie Hevea brasiliensis nas diversas partes da planta e, que o efeito de toxicidade ao alumínio no seu crescimento só é verificado em concentrações superiores a $15 \mathrm{mmol}_{\mathrm{c}} \cdot \mathrm{dm}^{-3}$.

Machado (1988) verificou que a espécies Vochysia thyrsoidea não cresce na ausência de alumínio, nem em solos calcários; as mudas crescendo em solos calcários apresentaram clorose e necrose foliar e pouco crescimento, quando transplantadas para solos ácidos recuperaram as folhas necróticas e retomaram o crescimento. A única diferença constatada quanto à análise foliar foram altas concentrações de alumínio nas mudas transplantadas para os solos ácidos. Resultados similares foram obtidos por Haridasan (1988) constatando que as mudas de Miconia albicans pararam de crescer nos solos calcários e retomaram o crescimento quando algumas raízes foram imersas em uma solução de cloreto de alumínio, com um aumento na concentração de alumínio na folha. 


\subsection{Mecanismos de tolerância ao alumínio}

De acordo com Foy (1988), os mecanismos de tolerância classificam-se em: a) mecanismos de exclusão: consiste-se na imobilização do Al na parede celular, na permeabilidade seletiva da membrana plasmática, na alteração de $\mathrm{pH}$ induzida na rizosfera (apenas em monocotiledoneas), e na exudação de complexantes e/ou quelantes; b) mecanismos de tolerância interna ao alumínio acumulado: consiste-se na complexação ou quelatização do alumínio no citoplasma, na compartimentação no vacúolo, na presença de proteínas especializadas na ligação com o alumínio, na evolução de enzimas tolerantes ao alumínio e na resistência da membrana plasmática em sofrer alterações de comportamento.

Estudos na área de bioquímica indicam que diversos mecanismos de defesa são acionados tanto para impedir a entrada do alumínio, como para evitar os efeitos tóxicos do íon dentro da célula. Dentre os mecanismos bioquímicos destacam-se aqueles que envolvem competição por sítios de absorção de nutrientes, interações com componentes lipídios de membrana, os que alteram a sua permeabilidade e inibição do processo de mitose nos meristemas apicais das raízes (Paiva, 1999).

O mecanismo de tolerância mais freqüentemente proposto é o de exclusão iônica, que consiste na redução da atividade do alumínio pela exudação de complexante por ácidos orgânicos, reduzindo a concentração de alumínio na rizosfera e interfere na absorção e translocação do íon na planta (Brown \& Ambler, 1974; Butz \& Jackson, 1977; Cambraia et al., 1983; Bennet et al.,1987; Schottelndreier \& Grerup-Falkengren, 1999; Ahonen-Jonnarth et al., 2000). Gonçalves et. al (1999) verificaram em plantas tolerante de sorgo, que o alumínio parece estimular a síntese e/ou inibir a degradação das ácidos orgânicos, e, as enzimas ligadas ao metabolismos desse ácidos orgânicos apresentam no cultivar tolerante menor sensibilidade à toxidez de alumínio, quando comparado ao cultivar sensível. 
De acordo com alguns autores (Hampp \& Schanabl, 1975; Jackson et al., 1977; Alam \& Adams, 1979; Foy et al., 1965; Hecht-Buchholz \& Foy,1981; Furlani,1989; Carvalho, 1994; Tan \& Keltjens, 1995; Furtini et al., 1996) a tolerância diferencial ao alumínio está relacionada com a diferença na resistência à desorganização da membrana, onde plantas tolerantes apresentam maior resistência da membrana plasmática em sofrer alterações de comportamento e maior influência no funcionamento de canais iônicos transportadores de $\mathrm{H}^{+}$, aumentando a atividade das enzimas $\mathrm{H}^{+}$- ATPase e $\mathrm{H}^{+}$- PPase, indicando um mecanismo de tolerância onde cátions são mantidos dentro da célula $\mathrm{e}$ prótons, são bombeados para dentro do vacúolo, visando restaurar o equilíbrio iônico. Verstraeten \& Otiza (2000) estudando duas variedades de trigo, uma sensível e outra tolerante, submetidas a: $\mathrm{pH} 4,0$; baixa concentração de cálcio e incrementos de temperatura, verificaram que os fatores que afetaram a permeabilidade da membrana plasmática, também afetaram o acúmulo de alumínio e que a região de maior permeabilidade das membranas coincidiu com a de maior acúmulo de alumínio, concluindo que o acesso de alumínio, ao interior celular, das espécies sensíveis está relacionado com maior permeabilidade da membrana plasmática.

O alumínio influencia a morfologia da raiz, inibindo seu crescimento e restringindo sua superficie de absorção, e a capacidade de maior proliferação de raízes finas, por conseguinte, maior superfície radicular sob estresse de alumínio é um possível mecanismo de adaptação em ambientes distróficos, pois quanto maior a densidade de raízes maior exploração do volume de solo, aumentando os sítios de absorção, evitando a restrição na absorção de água e de nutrientes (Foy, 1984; Bennete et al.,1987; Berish \& Ewel,1988; Baligar et al., 1993; Gonçalves,1994).

Braccini et al. (1998), estudando genótipos de eucalipto, observaram que a tolerância ao alumínio está associada ao menor acúmulo e à maior absorção e eficiência no uso do fósforo e do cálcio e, à menor redução na translocação do alumínio para a parte aérea, admitindo que esta espécie tenha capacidade de manter a absorção e translocação de fósforo e de cálcio na presença do alumínio. Neves et al. (1982) avaliou o efeito de diferentes níveis de alumínio sobre o crescimento e à absorção de fósforo em 
eucalipto. Concluindo que o E. uropylla apresentou-se mais tolerante, pois a concentração de fósforo, na parte aérea, foi semelhante na presença e na ausência do alumínio, admitindo que esta espécie tenha evoluído em ambiente distrófico e, o $E$. cloeziana apresentou-se menos tolerante, teve o seu conteúdo de fósforo, na parte aérea e, nas raízes, reduzido a valores mínimos para maior concentrações de alumínio na solução do solo. $O$ autor acredita que a espécie menos tolerante possua mecanismo de exclusão do alumínio do metabolismo celular menos eficiente do que as demais espécies, e que o efeito da toxidez de alumínio nesta espécie está relacionado a absorção e/ou transporte de P.

Devido à nitrificação ser inibida nos solos ácidos, o amônio torna-se uma importante fonte de nitrogênio. Algumas espécies vegetais como o eucalipto, consideradas tolerantes ao alumínio, apresentam um mecanismo bem desenvolvido na absorção do amônio, podendo ser uma adaptação ecológicas, a solos ácidos, e também uma estratégia de economia de energia pela incorporação imediata do amônio ao esqueleto de carbono, e de economia de nitrogênio no sistema, pois ameniza a perda de nitrato por lixiviação devido ao decréscimo na nitrificação. Porém, algumas espécies tolerantes ao alumínio são caracterizadas pela habilidade em absorver eficientemente 0 nitrato, elevando o pH da rizosfera através da liberação de ânion, como conseqüência a insolubilização do alumínio (Foy et al., 1966). Segundo Vale (1982), deve-se então ter em mente, ao avaliar o efeito de qualquer fator sobre a absorção de nitrogênio, que as plantas variam muito na capacidade de absorver e utilizar as formas nitrogenadas

Um outro mecanismo proposto é a capacidade de troca de cátion da raiz. Blamey et al. (1992) estudaram a capacidade de troca cátion (CTC ) de raiz de duas espécies, sendo uma tolerante ao alumínio e a outra, sensível, observaram uma maior absorção de cátions de maior valência, por espécies sensíveis, quando comparadas a espécies tolerantes, devido ao deslocamento de cátions monovalentes na parede celular, concluindo que plantas com baixa CTC de raiz têm sido consideradas tolerantes e que a CTC de raiz está associada a mecanismos de tolerância presentes na parede celular. Segundo Manlio (1998) a CTC da raiz está diretamente ligada à quantidade de grupos 
carboxila e pectinas livres presentes na parede celular, e que uma planta tolerante ao alumínio se torna sensível, quando a sua camada de mucilagem, composta principalmente de ácidos poligalacturônicos, é removido, evidenciando o papel importante do cálcio no processo de tolerância ao alumínio. (Hue et al., 1986) relatam que plantas sensíveis tratadas com alumínio têm o seu crescimento radicular restaurado, quando tratadas com altas concentrações de cálcio, sugerindo que o cálcio estaria envolvido na tolerância ao alumínio, mais efetivamente no mecanismo de capacidade de troca de cátion de raiz. 


\section{MATERIAL E MÉTODOS}

O experimento foi conduzido durante o período de março de 2000 a janeiro de 2001, em casa de vegetação. Foram utilizadas amostras de terra da camada de 0 a $20 \mathrm{~cm}$ de profundidade de um solo caracterizado como Latossolo A moderado distrófico, textura média (em g kg-1, 240 de argila, 60 de silte e 700 de areia total), originário da região de cerrado, coletado na Estação Experimental de Itatinga, Itatinga-SP. Os atributos químicos das amostras de solos utilizadas no experimento, segundo os métodos descritos por Raij et al. (1987), foram: $\mathrm{pH}$ em $\mathrm{CaCl}_{2}=3,9 ; \mathrm{MO}=28 \mathrm{~g} \mathrm{dm}^{-3} ; \mathrm{P}$-resina $=$ $5 ; \mathrm{S}^{-\mathrm{SO}_{4}}{ }^{2-}=38 \mathrm{mg} \mathrm{dm}^{-3} ; \mathrm{K}=0,4 ; \mathrm{Ca}=0,4 ; \mathrm{Mg}=1 ; \mathrm{H}+\mathrm{Al}=58 ; \mathrm{Al}=15 ; \mathrm{SB}=2 ; \mathrm{T}=$ $60 \mathrm{mmol}_{\mathrm{c}} \mathrm{dm}^{-3} ; \mathrm{V}=3 \%$ e $\mathrm{m}=90 \%$. Os teores de micronutrientes extraídos pelo DTPA, segundo os métodos descritos por Lindsay \& Norvell (1978), foram: $\mathrm{Cu}=1,8, \mathrm{Zn}=0,3$, $\mathrm{Mn}=1,1, \mathrm{Fe}=41, \mathrm{e} \mathrm{B}=0,18 \mathrm{mg} \mathrm{dm}^{-3}$.

Utilizaram-se três espécies de Eucalyptus (E. grandis, E. urophylla e o híbrido $E$. grandis vs. Eucalyptus urophylla) e duas espécies de Pinus (P. oocarpa e P. caribaea var. hondurensis).

Os tratamentos, aplicados antes do plantio, foram os seguintes:

AB-250P: Adubação básica - $50 \mathrm{mg}$ de N, $100 \mathrm{mg}$ de K, $250 \mathrm{mg}$ de $\mathrm{P}$ e $45 \mathrm{mg}$ de S $\mathrm{kg}^{-1}$ de solo;

CCO-250P: Adubação básica mais $\mathrm{CaCO}_{3}$ e $\mathrm{MgCO}_{3}$, na relação estequiométrica de 4:1, de modo a elevar o teor de $\mathrm{Ca}+\mathrm{Mg}$ para 10 mmol $_{\mathrm{c}} \mathrm{kg}^{-1}$ de solo; 
SCO-250P: Adubação básica mais $\mathrm{CaSO}_{4}$ e $\mathrm{MgCl}_{2}$, de modo a elevar o teor de $\mathrm{Ca}^{2+}+$ $\mathrm{Mg}^{2+}$ para 10 mmol $_{\mathrm{c}} \mathrm{kg}^{-1}$ de solo; e

SCO-250P: Adubação básica com aplicação de $125 \mathrm{mg} \mathrm{P} \mathrm{kg}^{-1}$ de solo mais $\mathrm{CaSO}_{4} \mathrm{e}$ $\mathrm{MgCl}_{2}$, de modo a elevar o teor de $\mathrm{Ca}^{2+}+\mathrm{Mg}^{2+}$ para $10 \mathrm{mmol}_{\mathrm{c}} \mathrm{kg}^{-1}$ de solo.

Efetuou-se em todos os tratamentos adubação de cobertura com N $(25+25+50$ $\mathrm{mg} \mathrm{kg}{ }^{-1}$ de solo) e $\mathrm{S}\left(22,5+22,5+45 \mathrm{mg} \mathrm{kg}^{-1}\right.$ de solo), aplicados aos 60, 120 e 180 dias após a semeadura das espécies de Eucalyptus e Pinus, na forma de solução aquosa. $\mathrm{O}$ fornecimento de micronutrientes foi realizado segundo a recomendação da EMBRAPA (1979), aos 100 dias após a semeadura do eucalipto e do pinus (todas as fontes p.a.). Os atributos químicos das amostras de solo, após a aplicação dos tratamentos, são apresentados na Tabela 1 .

Após a adubação básica, a terra foi acondicionada em vasos de polietileno (com capacidade para $4 \mathrm{~kg}$ de terra), e irrigada para obter uma umidade em torno da capacidade de retenção de água, que foi mantido durante a condução do experimento, utilizando-se água destilada.

As sementes de eucalipto e de pinus foram germinadas em areia lavada e, ao atingirem aproximadamente $5 \mathrm{~cm}$ de altura, as plântulas foram repicadas para os vasos contendo os tratamentos. Sessenta dias após a repicagem, efetuou-se o desbaste, mantendo-se duas plantas por vaso.

O delineamento experimental utilizado foi do tipo blocos ao acaso, em esquema fatorial 3x4 para as espécies de Eucalyptus, sendo 3 os níveis de fator "espécies", e 4 os níveis de fator "adubação", e $2 \times 4$ para as espécies de Pinus, sendo 2 os níveis de fator "espécies", e 4 os níveis de fator "adubação", perfazendo um total de 36 e 24 unidades experimentais, respectivamente. Cada bloco foi constituído de um vaso, no qual foram cultivados duas plantas, para os vasos com eucalipto e duas plantas para os vasos com pinus. 
Tabela 1 Atributos químicos ${ }^{(1)}$ das amostras de solo, após a aplicação dos tratamentos ${ }^{(2)}$.

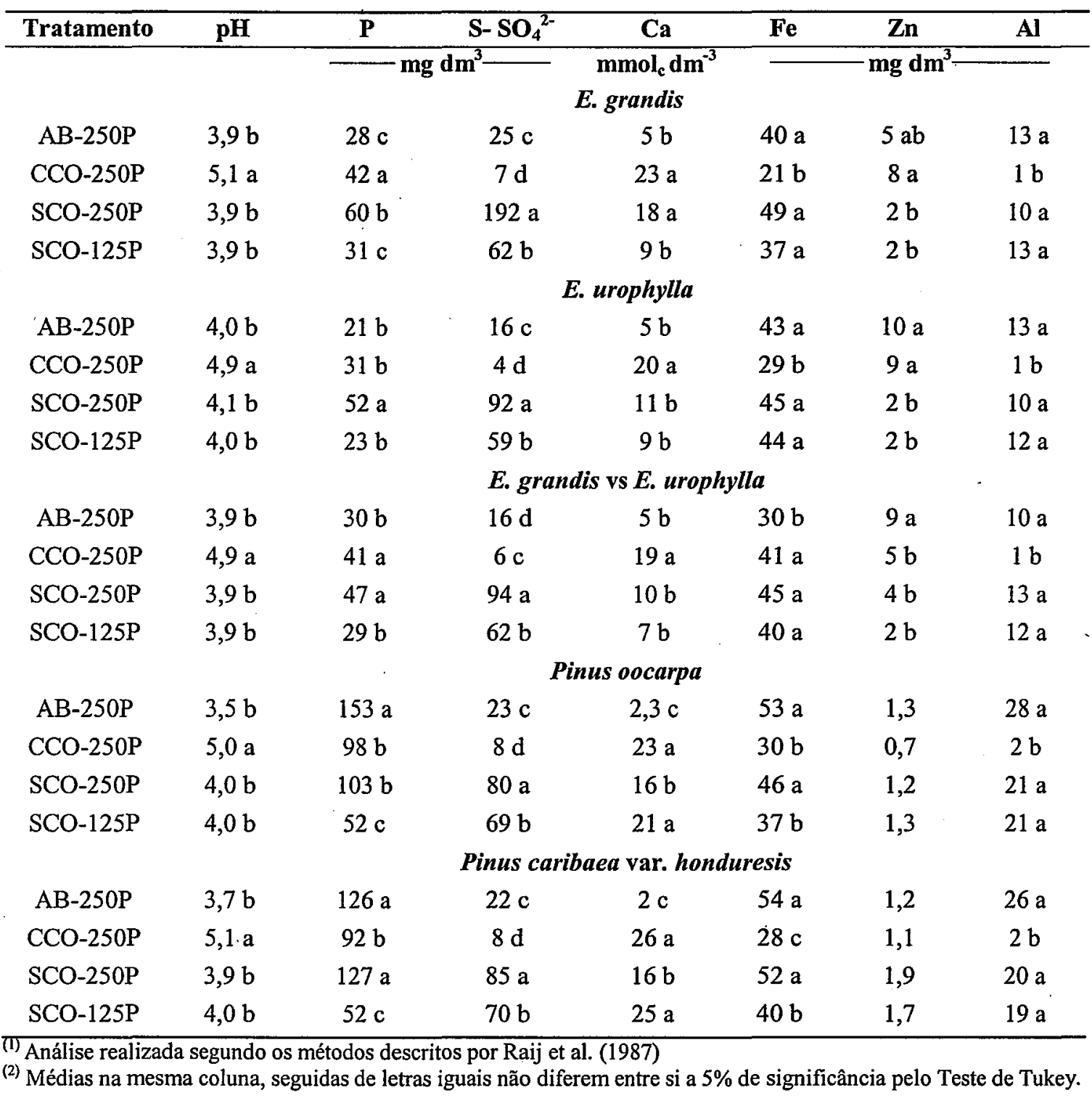

Após 210 e 300 dias da semeadura, foram realizadas as avaliações de crescimento para o eucalipto e para o pinus, respectivamente. As medições em altura foram feitas a partir do colo da planta até o ponto de inserção da folha mais jovem, e os diâmetros foram medidos no colo da planta. As plantas foram colhidas e secionadas próximo ao coleto. O material vegetal foi separado em caule, galhos, folhas e sistema radicular. Os componentes das mudas foram pesados, imediatamente, após a colheita, e submetidos à secagem em estufa a $65^{\circ} \mathrm{C}$, até massa constante. $\mathrm{O}$ processamento das 
amostras e análise de macro e micronutrientes seguiram as metodologias descritas por Malavolta et al. (1997).

As raízes foram separadas das amostras de solo por peneiragem e catação manual e lavadas com água destilada. Foi utilizado como critério para a separação de raízes vivas e mortas, a friabilidade e a coloração. As raízes vivas apresentavam cores claras, tendendo para o amarelado e, a raízes mortas, coloração mais escura e friáveis. As raízes foram classificadas em raízes finas (ativas na absorção de nutrientes) e raízes grossas, conforme os critérios fisiológicos propostos por Lyford (1975). Segundo este pesquisador, são consideradas raízes finas aquelas com diâmetro $\leq 3 \mathrm{~mm}$, porque, geralmente, não apresentam espessamento do xilema secundário e possuem floema pouco desenvolvido, muito permeáveis à absorção de água e nutrientes. As raízes com diâmetro $\leq 1 \mathrm{~mm}$ são as que mais contribuem para a absorção de água e nutrientes. Para as espécies de Eucalyptus e de Pinus foram separadas duas classes de raízes finas: a) raízes com diâmetro $\leq 1 \mathrm{~mm}$ e b) raízes com diâmetro entre 1 e $3 \mathrm{~mm}$. O comprimento radicular foi estimado pelo sistema SIARCS (Sistema Integrado para Análise de Raízes e Cobertura do Solo), que consiste no processamento e análise de imagens digitais, conforme metodologia apresentada por Jorge et al. (1993). Inicialmente, as raízes foram secionadas em partes de aproximadamente $5 \mathrm{~cm}$, e distribuídas em uma bandeja de vidro de $15 \times 21 \mathrm{~cm} \mathrm{e} 1 \mathrm{~cm}$ de altura ( $2 \mathrm{~mm}$ de espessura). Sobre estas foi colocado uma lâmina d'água, suficiente para cobri-las. A bandeja foi colocada sobre um "scanner" de mesa de resolução espacial de $1200 \mathrm{dpi}$, o qual digitalizou-se as imagens das raízes, transferindo-as automaticamente para o arquivo no computador. A partir desta fase, por meio do sistema SIARCS, as imagens foram binarizadas e esqueletonizadas para o cálculo do comprimento radicular. Com o comprimento radicular e o volume do vaso estimou-se a densidade de raízes finas.

Após a colheita das mudas, amostras de solo de cada vaso foram secas em estufa com circulação forçada de ar $\left(45^{\circ} \mathrm{C}\right)$ até apresentarem a sua massa constante. Foram avaliados os seguintes atributos: $\mathrm{pH}$, carbono orgânico total, $\mathrm{P}, \mathrm{Ca}, \mathrm{Mg}, \mathrm{S}$ e Al trocáveis, $\mathrm{H}+\mathrm{Al}$, soma de bases (SB), capacidade de troca catiônica $(\mathrm{T})$, segundo os métodos 
descritos por Raij et al. (1987). Os micronutrientes, ferro e zinco foram extraídos com DTPA e analisados segundo os métodos descritos por Lindsay \& Norvell (1978).

A determinação da capacidade de troca de cátions (CTC, em $\mathrm{mmol}_{\mathrm{c}} \mathrm{kg}^{-1}$ ) das raízes finas (apenas as com diâmetro $\leq 1 \mathrm{~mm}$ ) foi realizada, segundo o método descrito por CrooKe (1964). O método consiste em saturar a CTC da raiz com íons $\mathrm{H}^{+}$usando $\mathrm{HCl} 0,1 \mathrm{~mol} \mathrm{~L}^{-1} \mathrm{e}$, em seguida, o excesso do ácido é retirado com água destilada. Os íons $\mathrm{H}^{+}$adsorvidos à CTC das raízes são removidos com uma solução de $\mathrm{KCl} 1 \mathrm{~mol} \mathrm{~L}^{-1}$ a pH 7. Por titulação com $\mathrm{KOH} 0,1 \mathrm{~mol} \mathrm{~L} \mathrm{~L}^{-1}$, determina-se a quantidade de $\mathrm{H}^{+}$adsovido, estimando-se assim a CTC de raízes.

Para avaliar o efeito dos tratamentos, foi utilizada a análise de variância (ANOVA). As médias foram comparadas pelo teste de Tukey. As relações entre densidade de raízes e os teores de $\mathrm{Ca}, \mathrm{P}$, soma de bases, saturação de alumínio e pH foram avaliadas por meio de análises de correlação simples (Pearson). Foi utilizado o programa estatístico SAS (SAS Institute, 1991). 


\section{RESULTADOS E DISCUSSÃO}

\subsection{Efeito do alumínio sobre o crescimento da planta}

O crescimento em altura, em diâmetro do colo, em produção de matéria seca da parte aérea e do sistema radicular do híbrido $E$. grandis vs. $E$.urophylla foi maior do que o das demais espécies (Tabela 2). Deduz-se que este híbrido é geneticamente mais produtivo ou adaptou-se melhor às condições ambientais (de temperatura, de UR e de solo) do que as demais espécies. Em condições de campo, tem sido verificado que este híbrido é freqüentemente superior às demais espécies, em diferentes condições edafoclimáticas, sugerindo que seu potencial genético é mais produtivo. Proporcionalmente, este híbrido produziu muito mais matéria seca na parte aérea, para uma menor quantidade de matéria seca radicular. Esta menor locação de fotoassimilados no sistema radicular e maior na parte aérea, destacadamente a foliar, é indicativo de sua maior capacidade de adaptação em solos ácidos, com altos teores de alumínio trocável.

As espécies de Eucalyptus e de Pinus não apresentaram diferenças de crescimento em altura, diâmetro do colo e produção de matéria seca da parte aérea entre os diferentes níveis de saturação de alumínio e disponibilidade de nutrientes no solo (Tabela 2). Entretanto, apresentaram diferenças em relação a produção de matéria seca de raízes finas $(<1 \mathrm{~mm})$, aos 210 e 300 dias de idade, respectivamente. Verificou-se para todas as espécies de Eucalyptus e de Pinus maior produção de matéria seca de raízes finas $(<1 \mathrm{~mm}$ ) nos tratamentos $\mathrm{AB}-250 \mathrm{P}$ e SCO-125P e menor nos demais tratamentos, que receberam maior dosagem de fósforo ou calagem. Segundo Foy (1992), elevados teores de alumínio trocável podem, às vezes, diminuir substancialmente a produção das culturas sem apresentar sintomas evidentes na parte área das plantas, ao contrário do 
sistema radicular. Enquanto as raízes podem ser diretamente afetadas em nível celular, os efeitos na parte aérea, geralmente, resultam de fatores indiretos, como a diminuição da absorção de água e de nutrientes, principalmente, de $\mathrm{Ca}$ e de $\mathrm{P}$. Quando a disponibilidade destes nutrientes é adequada, mesmo com elevadas concentrações de alumínio, o crescimento da parte aérea pode ser pouco afetado (Costa, 1986). Este efeito deve ser mais evidente na fase de mudas, em que a demanda de água e nutrientes é baixa.

As espécies de Pinus não apresentaram diferenças de crescimento em altura, diâmetro do colo e produção de matéria seca da parte aérea e do sistema radicular, entre si (Tabela 2). De modo geral, aos 300 dias de idade, estas espécies apresentaram menor crescimento que as de Eucalyptus aos 210 dias de idade. Em condições de campo, resultados similares foram relatados por Reissmann \& Wisnemski (2000), que, estudando aspectos nutricionais de plantios de Pinus e Eucalyptus, verificaram que o eucalipto apresentou maior crescimento e produção de biomassa em solos com menores disponibilidade de nutrientes.

Todas as plantas das espécies estudadas apresentaram raízes longas, filiformes e de superfícies externas regulares e brancas, com raízes laterais bem acima da região apical da raiz principal. Pode-se inferir que alguns mecanismos de proteção ou exclusão ocorram no sentido de evitar a translocação de alumínio até o protoplasma do tecido radicular dessas espécies, evitando a inibição do processo de divisão celular e possibilitando maior proliferação de raízes finas. Um dos possíveis mecanismos é a complexação do alumínio por fosfato e ácidos orgânicos, resultando em compostos com baixa fitotoxicidade em comparação às espécies monoméricas de alumínio (Huang \& Bachelard, 1993). 
Tabela 2 Crescimento em altura (Alt), diâmetro do colo (Dc) e produção de matéria seca $(F=$ folha, $G=$ galho, $\mathrm{C}=$ caule, $\mathrm{PA}=$ parte área, $\mathrm{R}=$ raiz, $\mathrm{RT}=$ raiz total, $\mathrm{PT}=$ planta total) da parte aérea, das raízes das diferentes espécies de Eucalyptus e Pinus em função dos tratamentos ${ }^{(1)}$.

\begin{tabular}{|c|c|c|c|c|c|c|c|c|c|c|}
\hline \multirow{3}{*}{ Tratamento } & \multirow{3}{*}{ Alt } & \multirow{3}{*}{ Dc } & \multicolumn{6}{|c|}{ Matéria Seca } & \multirow{3}{*}{$\mathbf{R T}$} & \multirow{3}{*}{ PT } \\
\hline & & & \multirow[t]{2}{*}{$\mathbf{F}$} & \multirow[t]{2}{*}{$\mathbf{G}$} & \multirow[t]{2}{*}{$\mathbf{C}$} & \multirow[t]{2}{*}{$\mathbf{P A}$} & & & \\
\hline & & & & & & & $<1 \mathrm{~mm}$ & \multirow{2}{*}{$\begin{array}{l}\mathrm{R} \\
>1 \mathrm{~mm} \\
\end{array}$} & & \\
\hline & & - & & & & & $\mathrm{muda}^{-1}$ & & & \\
\hline & \multicolumn{10}{|c|}{ E. grandis } \\
\hline $\mathrm{AB}-250 \mathrm{P}$ & $51,3 \mathrm{~B}$ & $6,0 \mathrm{~B}$ & $7,9 \mathrm{~B}$ & $1,6 \mathrm{~B}$ & $2,2 \mathrm{~B}$ & $12 \mathrm{~B}$ & $6,8 \mathrm{a} \mathrm{B}$ & $0,6 \mathrm{~B}$ & $7,4 \mathrm{a} \mathrm{B}$ & $19,4 \mathrm{~B}$ \\
\hline $\mathrm{CCO}-250 \mathrm{P}$ & $54,0 \mathrm{~B}$ & $6,0 \mathrm{~B}$ & $8,4 \mathrm{~B}$ & $1,8 \mathrm{~B}$ & $2,5 \mathrm{~B}$ & $13 \mathrm{~B}$ & $5,0 \mathrm{~b} \mathrm{~B}$ & $0,6 \mathrm{~B}$ & $5,6 \mathrm{~b} \mathrm{~B}$ & $18,6 \mathrm{~B}$ \\
\hline SCO-125P & $51,6 \mathrm{~B}$ & $6,6 \mathrm{~B}$ & $8,0 \mathrm{~B}$ & $1,7 \mathrm{~B}$ & $2,2 \mathrm{~B}$ & $12 \mathrm{~B}$ & $6,7 \mathrm{a} \mathrm{B}$ & $0,7 \mathrm{~B}$ & $7,4 \mathrm{a} \mathrm{B}$ & $19,4 \mathrm{~B}$ \\
\hline \multirow[t]{2}{*}{ SCO-250P } & $56,0 \mathrm{~B}$ & $6,8 \mathrm{~B}$ & $8,5 \mathrm{~B}$ & $1,9 \mathrm{~B}$ & $2,7 \mathrm{~B}$ & $13 \mathrm{~B}$ & $5,1 \mathrm{~b} \mathrm{~B}$ & $0,6 \mathrm{~B}$ & $5,7 \mathrm{~b} \mathrm{~B}$ & $18,1 \mathrm{~B}$ \\
\hline & \multicolumn{10}{|c|}{ E. urophylla } \\
\hline $\mathrm{AB}-250 \mathrm{P}$ & $57,5 \mathrm{~B}$ & $6,7 \mathrm{~B}$ & $8,6 \mathrm{~B}$ & $2,0 \mathrm{~B}$ & $2,4 \mathrm{~B}$ & $13 \mathrm{~B}$ & $7,4 \mathrm{a} \mathrm{B}$ & $0,7 \mathrm{~B}$ & $8,1 \mathrm{a} \mathrm{B}$ & $21 \mathrm{~B}$ \\
\hline $\mathrm{CCO}-250 \mathrm{P}$ & $59,0 \mathrm{~B}$ & $7,1 \mathrm{~B}$ & $8,6 \mathrm{~B}$ & $2,0 \mathrm{~B}$ & $2,8 \mathrm{~B}$ & $13 \mathrm{~B}$ & $5,9 \mathrm{~b} \mathrm{~B}$ & $0,8 \mathrm{~A}$ & $6,7 \mathrm{~b} \mathrm{~B}$ & $20 \mathrm{~B}$ \\
\hline SCO-125P & $58,5 \mathrm{~B}$ & $6,4 \mathrm{~B}$ & $8,1 \mathrm{~B}$ & $1,9 \mathrm{~B}$ & $2,8 \mathrm{~B}$ & $13 \mathrm{~B}$ & 7,5a B & $0,8 \mathrm{~B}$ & $8,3 \mathrm{a} \mathrm{B}$ & $21 \mathrm{~B}$ \\
\hline \multirow[t]{2}{*}{ SCO-250P } & $60,0 \mathrm{~B}$ & $7,0 \mathrm{~B}$ & $8,6 \mathrm{~B}$ & $2,3 \mathrm{~B}$ & $3,1 \mathrm{~B}$ & $14 \mathrm{~B}$ & $6,0 \mathrm{bB}$ & $0,8 \mathrm{~A}$ & $6,8 \mathrm{~b} \mathrm{~B}$ & $21 \mathrm{~B}$ \\
\hline & \multicolumn{10}{|c|}{ E.grandis vs. E. urophylla } \\
\hline $\mathrm{AB}-250 \mathrm{P}$ & $72,5 \mathrm{~A}$ & $9,8 \mathrm{~A}$ & $11 \mathrm{~A}$ & $2,9 \mathrm{~A}$ & $3,3 \mathrm{~A}$ & $19 \mathrm{~A}$ & $9,0 \mathrm{a} A$ & $0,9 \mathrm{~A}$ & $9,9 \mathrm{aA}$ & $29 \mathrm{~A}$ \\
\hline $\mathrm{CCO}-250 \mathrm{P}$ & $70,2 \mathrm{~A}$ & $9,0 \mathrm{~A}$ & $12 \mathrm{~A}$ & $3.0 \mathrm{~A}$ & $3,7 \mathrm{~A}$ & $21 \mathrm{~A}$ & $8,1 \mathrm{bA}$ & $0,8 \mathrm{~A}$ & $8,9 \mathrm{~b} \mathrm{~A}$ & $30 \mathrm{~A}$ \\
\hline SCO-125P & $74,0 \mathrm{~A}$ & $8,4 \mathrm{~A}$ & $11 \mathrm{~A}$ & $2,8 \mathrm{~A}^{\prime}$ & $3,4 \mathrm{~A}$ & $20 \mathrm{~A}$ & $9 ; 1 \mathrm{a} \mathrm{A}$ & $0,9 \mathrm{~A}$ & $10 \mathrm{a} \mathrm{A}$ & $30 \mathrm{~A}$ \\
\hline \multirow[t]{2}{*}{ SCO-250P } & $76,0 \mathrm{~A}$ & $9,1 \mathrm{~A}$ & $11 \mathrm{~A}$ & $3,1 \mathrm{~A}$ & $3,7 \mathrm{~A}$ & $20 \mathrm{~A}$ & $8,0 \mathrm{bA}$ & $0,9 \mathrm{~A}$ & $8,9 \mathrm{~b} \mathrm{~A}$ & $29 \mathrm{~A}$ \\
\hline & \multicolumn{10}{|c|}{ Pinus oocarpa } \\
\hline $\mathrm{AB}-250 \mathrm{P}$ & 41,0 & 4,8 & 10,2 & - & 1,59 & 11,8 & $4,9 a$ & 0,4 & $5,49 a$ & 17,3 \\
\hline $\mathrm{CCO}-250 \mathrm{P}$ & 42,0 & 5,0 & 10,5 & - & 1,88 & 12,4 & $3,9 b$ & 0,3 & $4,32 b$ & 19,7 \\
\hline SCO-125P & 43,0 & 5,0 & 12,0 & - & 2,00 & 12,4 & $5,2 \mathrm{a}$ & 0,3 & $5,60 \mathrm{a}$ & 17,6 \\
\hline \multirow[t]{2}{*}{ SCO-250P } & 44,0 & 6,2 & 11,8 & - & 1,80 & 13,6 & $4,0 \mathrm{~b}$ & 0,4 & $4,50 \mathrm{~b}$ & 18,1 \\
\hline & \multicolumn{10}{|c|}{ Pinus caribaea var. hondurensis } \\
\hline $\mathrm{AB}-250 \mathrm{P}$ & 46,0 & 5,2 & 10 & - & 1,55 & 11,6 & $5,00 \mathrm{a}$ & 0,3 & $5,4 a$ & 17,0 \\
\hline $\mathrm{CCO}-250 \mathrm{P}$ & 49,0 & 5,0 & 9,9 & - & 1,21 & 11,1 & $4,00 \mathrm{~b}$ & 0,2 & $4,3 b$ & 15,4 \\
\hline SCO-125P & 48,0 & 5,5 & 11 & - & 1,55 & 12,6 & $5,60 \mathrm{a}$ & 0,3 & $6,0 \mathrm{a}$ & 18,6 \\
\hline SCO-250P & 49,0 & 5,6 & 11 & - & 1,30 & 12,3 & $4,10 b$ & 0,4 & $4,6 b$ & 16,9 \\
\hline
\end{tabular}

(1) Médias na mesma coluna, seguidas de letras iguais não diferem entre si a $5 \%$ de significância pelo Teste de Tukey. Diferença entre tratamentos (letras minúsculas) e espécies (letras maiúscula).

O E. grandis apresentou maior densidade de raízes do que E. urophylla e este maior do que o híbrido E. grandis vs. E. urophylla, nos tratamentos AB-250P, SCO-125, e SCO-250 (Tabela 3). Não houve diferenças entre as espécies no tratamento CCO$250 \mathrm{P}$. 
Tabela 3 Densidade de raizes finas $(<1 \mathrm{~mm})$ para as diferentes espécies e tratamentos ${ }^{(1)}$.

\begin{tabular}{lcccc}
\hline \multirow{2}{*}{ Espécie } & \multicolumn{4}{c}{ Densidade de raízes finas } \\
\cline { 2 - 5 } & AB-250P & CCO-250P & SCO-125P & SCO-250P \\
\cline { 2 - 5 } E.grandis & $0,20 \mathrm{aA}$ & $0,12 \mathrm{dA}$ & $0,18 \mathrm{bA}$ & $0,15 \mathrm{cA}$ \\
E. urophylla & $0,18 \mathrm{aB}$ & $0,12 \mathrm{dA}$ & $0,17 \mathrm{bB}$ & $0,14 \mathrm{cB}$ \\
E.urophylla vs. E.grandis & $0,15 \mathrm{aC}$ & $0,11 \mathrm{cB}$ & $0,15 \mathrm{aC}$ & $0,12 \mathrm{bC}$ \\
média & 0,18 & 0,12 & 0,17 & 0,14 \\
& & & & \\
Pinus oocarpa & $0,10 \mathrm{a}$ & $0,07 \mathrm{~b}$ & $0,09 \mathrm{a}$ & $0,07 \mathrm{~b}$ \\
Pinus caribaea var. hondurensis & $0,11 \mathrm{a}$ & $0,07 \mathrm{~b}$ & $0,09 \mathrm{a}$ & $0,07 \mathrm{~b}$ \\
média & 0,11 & 0,07 & 0,09 & 0,07 \\
(T) As médias com letras iguais não diferem entre si a 5\% de significância pelo Teste Tukey. Diferença entre \\
\multicolumn{2}{r}{ tratamentos (letras minúsculas) e espécies (letras maiúscula). } & &
\end{tabular}

As espécies de Pinus não apresentaram diferenças de densidade de raízes finas entre si (Tabela 3). Aos 300 dias de idade, estas espécies apresentaram menor densidade de raízes finas que as espécies de Eucalyptus aos 210 dias de idade. Uma provável explicação destas diferenças deve estar relacionada ao maior potencial de crescimento das espécies de Eucalyptus, como conseqüência, maior demanda de nutrientes e a maior densidade de raízes finas é um possível mecanismo de aumentar sua superficie de absorção. De modo geral, para todas as espécies de Eucalyptus e de Pinus, verificou-se que mais de $95 \%$ das raízes finas, pertenciam a classe de raiz $<1 \mathrm{~mm}$.

Verificou-se que as densidades de raízes finas correlacionaram-se positivamente com a saturação de alumínio e, negativamente, com o pH e com as concentrações de cálcio, fósforo e a soma de bases do solo (Tabela 4). Portanto, nos tratamentos com menor disponibilidade de bases e maior concentração de alumínio, verificou-se maior densidade de raízes finas. De acordo com Gonçalves \& Mello (2000) a menor densidade de raiz em sítios florestais mais produtivos, geralmente com solos mais férteis e, o inverso, em sítios menos produtivos, mostram que as árvores, por meio de seus sistemas radiculares, possuem grande capacidade de interação com os atributos do solo, como um mecanismo que permite as raízes ampliar ou reduzir sua capacidade de absorção de água e nutrientes, segundo a disponibilidade no solo. 
Tabela 4 Coeficientes de correlação simples entre alguns atributos químicos das amostras de terra e a densidade de raizes finas entre os tratamentos ${ }^{(1)}$ para as diferentes espécies: $E$. grandis (EG), $E$. urophylla (EU), hibrido E. grandis vs. E. urophylla (EG vs. EU), Pinus oocarpa (PO) e Pinus caribaea var. hondurensis (PC).

\begin{tabular}{|c|c|c|c|c|c|}
\hline \multirow[t]{2}{*}{ Espécie } & \multirow[t]{2}{*}{ Atributo } & \multicolumn{4}{|c|}{ Tratamento } \\
\hline & & AB-250P & SCO-125P & SCO-250P & CCO-250P \\
\hline \multirow[t]{5}{*}{ EG } & Ca trocável $\left(\mathrm{mmol}_{\mathrm{c}} \mathrm{dm}^{-3}\right)$ & $-0,45^{0,05}$ & $-0,42^{0,05}$ & $-0,33^{0,05 s}$ & $-0,31^{0,05}$ \\
\hline & P resina $\left(\mathrm{mg} \mathrm{dm} \mathrm{d}^{-3}\right)$ & $-0,48^{0,05}$ & $-0,32^{0,05}$ & $-0,32^{0,05}$ & $-0,38^{0,05}$ \\
\hline & soma de bases $\left(\mathrm{mmol}_{\mathrm{c}} \mathrm{dm}^{-3}\right)$ & $-0,33^{0,05}$ & $-0,39^{0,05}$ & $-0,34^{0,05}$ & $-0,25^{0,05}$ \\
\hline & $\mathrm{pH} \mathrm{em} \mathrm{CaCl} 20,01 \mathrm{M}$ & $-0,34^{0,05}$ & $-0,30^{0,05}$ & $-0,29^{0,05}$ & $-0,32^{0,05}$ \\
\hline & $\mathrm{m}(\%)$ & $0,49^{0,05}$ & $0,44^{0,05}$ & $0,36^{0,05}$ & $0,34^{0,05}$ \\
\hline \multirow[t]{5}{*}{ EU } & Ca trocável $\left(\mathrm{mmol}_{\mathrm{c}} \mathrm{dm}^{-3}\right)$ & $-0,33^{0,05}$ & $-0,30^{0,05}$ & $-0,25^{0,05}$ & $-0,29^{0,05}$ \\
\hline & $P$ resina $\left(\mathrm{mg} \mathrm{dm}^{-3}\right)$ & $-0,35^{0,05}$ & $-0,38^{0,05}$ & $-0,24^{0,05}$ & $-0,25^{0,05}$ \\
\hline & soma de bases $\left(\mathrm{mmol}_{\mathrm{c}} \mathrm{dm}^{-3}\right)$ & $-0,34^{0,05}$ & $-0,33^{0,05}$ & $-0,26^{0,05}$ & $-0,23^{0,05}$ \\
\hline & $\mathrm{pH}$ em $\mathrm{CaCl}_{2} 0,01 \mathrm{M}$ & $-0,39^{0,05}$ & $-0,32^{0,05}$ & $-0,20^{0,05}$ & $-0,24^{0,05}$ \\
\hline & $\mathrm{m}(\%)$ & $0,36^{0,05}$ & $0,32^{0,05}$ & $0,36^{0,05}$ & $0,38^{0,05}$ \\
\hline \multirow[t]{5}{*}{ EG vs. EU } & Ca trocável $\left(\mathrm{mmol}_{\mathrm{c}} \mathrm{dm}^{-3}\right)$ & $-0,35^{0,05}$ & $-0,27^{0,05}$ & $-0,25^{0,05 s}$ & $-0,29^{0,05}$ \\
\hline & $\mathrm{P}$ resina $\left(\mathrm{mg} \mathrm{dm}^{-3}\right)$ & $-0,31^{0,05}$ & $-0,29^{0,05}$ & $-0,28^{0,05}$ & $-0,28^{0,05}$ \\
\hline & soma de bases $\left(\mathrm{mmol}_{\mathrm{c}} \mathrm{dm}^{-3}\right)$ & $-0,38^{0,01}$ & $-0,37^{0,05}$ & $-0,36^{0,05}$ & $-0,25^{0,05}$ \\
\hline & $\mathrm{pH}$ em $\mathrm{CaCl}_{2} 0,01 \mathrm{M}$ & $-0,39^{0,05}$ & $-0,28^{0,05}$ & $-0,26^{0,05}$ & $-0,20^{0,05}$ \\
\hline & $\mathrm{m}(\%)$ & $0,36^{0,05}$ & $0,34^{0,05}$ & $0,33^{0,05}$ & $0,30^{0,05}$ \\
\hline \multirow[t]{5}{*}{ PO } & Ca trocável $\left(\mathrm{mmol}_{\mathrm{c}} \mathrm{dm}^{-3}\right)$ & $-0,42^{0,05}$ & $-0,33^{0,05}$ & $-0,39^{0,05 s}$ & $-0,30^{0,05}$ \\
\hline & $P$ resina $\left(\mathrm{mg} \mathrm{dm}^{-3}\right)$ & $-0,39^{0,05}$ & $-0,30^{0,05}$ & $-0,31^{0,05}$ & $-0,32^{0,05}$ \\
\hline & soma de bases $\left(\mathrm{mmol}_{\mathrm{c}} \mathrm{dm}^{-3}\right)$ & $-0,35^{0,01}$ & $-0,36^{0,05}$ & $-0,38^{0,05}$ & $-0,32^{0,05}$ \\
\hline & $\mathrm{pH} \mathrm{em} \mathrm{CaCl}_{2} \quad 0,01 \mathrm{M}$ & $-0,40^{0,05}$ & $-0,35^{0,05}$ & $-0,38^{0,05}$ & $-0,30^{0,05}$ \\
\hline & $\mathrm{m}(\%)$ & $0,40^{0,05}$ & $0,44^{0,05}$ & $0,43^{0,05}$ & $0,40^{0,05}$ \\
\hline \multirow[t]{5}{*}{$\mathrm{PC}$} & Ca trocável $\left(\mathrm{mmol}_{\mathrm{c}} \mathrm{dm}^{-3}\right)$ & $-0,45^{0,05}$ & $-0,35^{0,05}$ & $-0,30^{0,05 s}$ & $-0,30^{0,05}$ \\
\hline & $P$ resina $\left(\mathrm{mg} \mathrm{dm}^{-3}\right)$ & $-0,39^{0,05}$ & $-0,34^{0,05}$ & $-0,40^{0,05}$ & $-0,37^{0,05}$ \\
\hline & soma de bases $\left(\mathrm{mmol}_{\mathrm{c}} \mathrm{dm}^{-3}\right)$ & $-0,40^{0,01}$ & $-0,40^{0,05}$ & $-0,42^{0,05}$ & $-0,38^{0,05}$ \\
\hline & $\mathrm{pH}$ em $\mathrm{CaCl}_{2} 0,01 \mathrm{M}$ & $-0,40^{0,05}$ & $-0,39^{0,05}$ & $-0,36^{0,05}$ & $-0,30^{0,05}$ \\
\hline & $\mathrm{m}(\%)$ & $0,39^{0,05}$ & $0,32^{0,05}$ & $0,38^{0,05}$ & $0,30^{0,05}$ \\
\hline
\end{tabular}

(1) valores sobrescritos referem-se aos níveis de significância das correlações.

Gonçalves (1994), em povoamentos adultos de Eucalyptus grandis, verificou alta correlação entre o crescimento de raízes finas e a concentração de alumínio trocável (correlação negativa) e concentrações de $\mathrm{Ca}$ e $\mathrm{Mg}$ trocáveis (correlação positiva). 
Também foi verificada relação linear negativa entre crescimento das árvores $\mathrm{e}$ densidades de raízes finas. De forma similar, Reis et al. (1987), em povoamentos adultos de E. grandis, verificaram maior produção de matéria seca do sistema radicular (tanto raizes grossas como finas) e menor da parte aérea em um Latossolo Vermelho-Amarelo (LVA) com maior deficiência hídrica e menor fertilidade relativamente a um outro LVA. Portanto, as árvores locaram mais fotoassimilados no sistema radicular, em solos com menor disponibilidade de água e nutrientes, reduzindo a produção de matéria seca da parte aérea, principalmente troncos, objetivo das plantações.

\subsection{Composição de nutrientes nos diferentes componentes das mudas}

Os teores de alumínio nas raízes das mudas de eucalipto e de pinus foram maiores nas plantas do tratamento $\mathrm{AB}-250 \mathrm{P}$ (Tabelas 5 e 6). $\mathrm{O}$ E. urophylla apresentou menor teor de alumínio nas raízes do que as outras espécies de Eucalyptus, que não apresentaram diferenças entre si, em todos os tratamentos. Na parte aérea, embora não haja diferenças entre as espécies de Eucalyptus, de modo geral, observa-se tendência do híbrido $E$. grandis vs $E$. urophylla apresentar menor teor de alumínio, seguido do $E$. urophylla.

Apesar do teor de alumínio na raiz ser elevado, não refletiu na produção de matéria seca da parte aérea do eucalipto e do pinus (Tabelas 5 e 6). Esta constatação sugere que o elevado teor de alumínio no sistema radicular, associado ao menor teor na parte aérea, é indício de algum mecanismo de retenção de alumínio nas raízes, evitando sua translocação para a parte aérea, o que poderia constituir uma das causas da alta tolerância de várias espécies de Eucalyptus à toxicidade de alumínio (Barros \& Novais, 1990). Esta suposta compartimentalização do alumínio em determinados sítios nas raízes, deve estar associado à adsorção do alumínio no complexo de troca catiônica das raízes ou à formação de quelatos com proteínas e ácidos orgânicos (Foy, 1988; Taylor, 1988). Furlani (1989) sugere que o suprimento de fósforo ao substrato de crescimento, ocasiona um efeito protetivo contra a injúria de alumínio devido a ocorrência de precipitados $\mathrm{Al}$ - fosfato na superfície da raiz inibindo a entrada do alumínio para o simplasto e em menor grau para o apoplasto. 
Tabela 5 Composição química ${ }^{(1)}$ dos diferentes componentes das espécies de Eucalyptus.

\begin{tabular}{|c|c|c|c|c|c|c|c|c|c|c|c|}
\hline Tratamento & $\mathbf{N}$ & $\mathbf{P}$ & $\mathbf{K}$ & $\mathrm{Ca}$ & Mg & $\mathbf{S}$ & $\mathbf{F e}$ & $\mathbf{Z n}$ & $\mathrm{Cu}$ & Mn & Al \\
\hline \multicolumn{12}{|c|}{$\begin{array}{l}\text { E. grandis } \\
\text { folha }\end{array}$} \\
\hline $\mathrm{AB}-250 \mathrm{P}$ & 7,3 & 1,6 & $6,1 \mathrm{aA}$ & $1,7 \mathrm{c}$ & $0,7 \mathrm{bB}$ & 1,7 & $220 \mathrm{~A}$ & $29 \mathrm{bB}$ & $9,7 \mathrm{aA}$ & $563 \mathrm{bA}$ & 210 \\
\hline $\mathrm{CCO}-250 \mathrm{P}$ & 6,9 & 1,3 & $3,4 \mathrm{bA}$ & $4,6 b$ & $2,1 \mathrm{aA}$ & 1,7 & $200 \mathrm{~A}$ & $13 \mathrm{cA}$ & $7,0 \mathrm{bA}$ & $110 \mathrm{cA}$ & 218 \\
\hline SCO-125P & 6,7 & 1,2 & $5,6 \mathrm{aA}$ & $6,4 a$ & $2,2 \mathrm{aA}$ & 1,0 & $168 \mathrm{~B}$ & $34 \mathrm{bA}$ & $6,0 \mathrm{bA}$ & $673 \mathrm{bA}$ & 270 \\
\hline SCO-250P & 7,0 & 1,1 & $5,6 \mathrm{aA}$ & $6,0 \mathrm{a}$ & $2,1 \mathrm{aA}$ & 1,4 & 177B & $46 \mathrm{aA}$ & $6,0 \mathrm{bA}$ & $887 \mathrm{aA}$ & 258 \\
\hline \multicolumn{12}{|c|}{ galho + caule } \\
\hline $\mathrm{CCO}-250 \mathrm{P}$ & 3,0 & $3,4 \mathrm{~b}$ & $6,3 b$ & $7,9 \mathrm{a}$ & $1,1 \mathrm{a}$ & 0,5 & $83 \mathrm{bA}$ & $13 \mathrm{cA}$ & $5,0 \mathrm{bA}$ & $82 \mathrm{cA}$ & $175 \mathrm{abA}$ \\
\hline SCO-125P & 2,9 & $2,9 b$ & $9,0 \mathrm{a}$ & $7,9 a$ & $1,0 \mathrm{a}$ & 0,5 & $187 \mathrm{aA}$ & $28 \mathrm{bA}$ & $9,0 \mathrm{aA}$ & $285 \mathrm{bA}$ & 195abA \\
\hline SCO-250P & 2,8 & $4,1 \mathrm{a}$ & $8,0 \mathrm{a}$ & $7,9 \mathrm{a}$ & $1,1 \mathrm{a}$ & $\begin{array}{r}0,6 \\
\text { raiz }\end{array}$ & $139 \mathrm{aA}$ & $50 \mathrm{aA}$ & $10 \mathrm{aA}$ & $276 \mathrm{bA}$ & $157 \mathrm{~b} \mathrm{~A}$ \\
\hline $\mathrm{AB}-250 \mathrm{P}$ & $5,9 \mathrm{~B}$ & $1,6 \mathrm{~b}$ & 3,6 & $1,6 \mathrm{cB}$ & $0,9 b$ & 2,2 & $15308 \mathrm{aA}$ & $117 \mathrm{aB}$ & $25 \mathrm{aA}$ & $159 \mathrm{aA}$ & $10455 \mathrm{aA}$ \\
\hline $\mathrm{CCO}-250 \mathrm{P}$ & $5,5 \mathrm{~B}$ & $1,0 \mathrm{c}$ & 4,3 & $3,3 \mathrm{bA}$ & $1,4 b$ & 2,0 & $7149 \mathrm{bB}$ & $135 \mathrm{aA}$ & $17 \mathrm{bA}$ & $85 \mathrm{bA}$ & $6602 \mathrm{bA}$ \\
\hline SCO-125P & $5,5 \mathrm{~B}$ & $1,8 \mathrm{~b}$ & 3,7 & $4,6 \mathrm{aA}$ & $2,1 \mathrm{a}$ & 2,0 & $8437 \mathrm{bAB}$ & $92 \mathrm{cB}$ & $21 \mathrm{aA}$ & $69 \mathrm{bA}$ & $6704 \mathrm{bA}$ \\
\hline $\mathrm{SCO}-250 \mathrm{P}$ & $5,6 \mathrm{~B}$ & $2,7 \mathrm{a}$ & 3,9 & $2,6 \mathrm{bA}$ & $1,4 \mathrm{~b}$ & 2,4 & $14364 \mathrm{aA}$ & $167 \mathrm{bB}$ & $27 \mathrm{aA}$ & $94 \mathrm{bA}$ & $7525 \mathrm{bA}$ \\
\hline \multicolumn{12}{|c|}{$\begin{array}{l}\text { E. urophylla } \\
\text { folha }\end{array}$} \\
\hline $\mathrm{AB}-250 \mathrm{P}$ & 7,5 & 1,6 & $6,6 \mathrm{aA}$ & $1,9 \mathrm{~b}$ & $0,8 \mathrm{bB}$ & 1,6 & $137 \mathrm{bB}$ & $43 \mathrm{aA}$ & $9,0 \mathrm{aA}$ & $399 \mathrm{bB}$ & $190 \mathrm{~b}$ \\
\hline CCO-250P & 6,4 & 1,4 & $2,7 \mathrm{cA}$ & $5,0 a$ & $2,3 \mathrm{aA}$ & 1,0 & $224 a A$ & $13 \mathrm{bA}$ & $2,6 \mathrm{cB}$ & $177 \mathrm{cA}$ & $209 b$ \\
\hline SCO-125P & 7,3 & 1,3 & $5,0 \mathrm{bA}$ & $6,2 \mathrm{a}$ & $2,4 \mathrm{aA}$ & 1,3 & $272 \mathrm{aA}$ & $46 \mathrm{aA}$ & $6,3 \mathrm{bA}$ & $738 \mathrm{aA}$ & $282 a$ \\
\hline SCO-250P & 6,7 & 1,5 & $5,1 \mathrm{bA}$ & $6,7 \mathrm{a}$ & $2,6 a A$ & 1,5 & $234 \mathrm{aA}$ & $42 \mathrm{aA}$ & $4,0 \mathrm{cB}$ & $761 \mathrm{aA}$ & $204 b$ \\
\hline $\mathrm{AB}-250 \mathrm{P}$ & 3,2 & $2,9 \mathrm{~b}$ & $4,7 \mathrm{~b}$ & $2,2 b$ & $0,4 \mathrm{~b}$ & \multicolumn{2}{|c|}{ caule+galho } & $47 a$ & $9,3 \mathrm{aA}$ & $301 \mathrm{bB}$ & \\
\hline CCO-250P & 2,9 & $3,1 \mathrm{~b}$ & $5,1 \mathrm{~b}$ & $6,6 a$ & $1,2 \mathrm{a}$ & 0,5 & $83 c$ & $19 b$ & $3,6 \mathrm{cB}$ & $137 \mathrm{cB}$ & $153 \mathrm{bA}$ \\
\hline SCO-125P & 3,2 & $4,3 a$ & $9,6 a$ & $7,3 a$ & $1,3 \mathrm{a}$ & 0,5 & $187 \mathrm{a}$ & $53 a$ & $9,0 \mathrm{aA}$ & $391 \mathrm{aB}$ & $235 \mathrm{aA}$ \\
\hline $\mathrm{SCO}-250 \mathrm{P}$ & 2,8 & $3,5 b$ & $8,7 \mathrm{a}$ & $7,6 \mathrm{c}$ & $1,4 a$ & 0,4 & $120 \mathrm{~b}$ & $54 \mathrm{a}$ & $7,0 \mathrm{bB}$ & $372 \mathrm{aB}$ & $173 \mathrm{bA}$ \\
\hline$A B-250 P$ & $4 a A$ & $2,1 \mathrm{a}$ & 4,0 & $2,7 \mathrm{bA}$ & 1,2 & $\begin{array}{c}\text { raiz } \\
2,5 a\end{array}$ & $10214 \mathrm{aB}$ & $120 \mathrm{bB}$ & $26 \mathrm{aA}$ & $72 \mathrm{bB}$ & $8158 \mathrm{aB}$ \\
\hline $\mathrm{CCO}-250 \mathrm{P}$ & $7,3 \mathrm{aA}$ & $1,3 b$ & 3,6 & $2,8 \mathrm{bA}$ & 1,0 & $1,3 b$ & $3937 \mathrm{cC}$ & $129 \mathrm{bA}$ & $16 \mathrm{bB}$ & $66 \mathrm{bA}$ & $5592 \mathrm{bA}$ \\
\hline SCO-125P & $7,2 \mathrm{aA}$ & $1,4 \mathrm{~b}$ & 4,2 & $4,1 \mathrm{aA}$ & 1,9 & $1,9 \mathrm{~b}$ & $7885 \mathrm{bB}$ & $151 \mathrm{bA}$ & $18 \mathrm{bA}$ & $90 \mathrm{aA}$ & $5565 \mathrm{bA}$ \\
\hline SCO-250P & $5,6 \mathrm{bB}$ & $1,9 a$ & 4,3 & $3,3 \mathrm{bA}$ & 1,3 & $1,4 \mathrm{~b}$ & $3712 \mathrm{cC}$ & $280 \mathrm{aA}$ & $18 \mathrm{bB}$ & $56 \mathrm{bA}$ & $4822 \mathrm{bB}$ \\
\hline \multicolumn{12}{|c|}{$\begin{array}{c}\text { E. grandis vs. E. urophylla } \\
\text { folha }\end{array}$} \\
\hline$A B-250 P$ & 7,8 & $1,8 \mathrm{a}$ & $7,2 \mathrm{aA}$ & $3,2 \mathrm{a}$ & $1,5 \mathrm{~A}$ & $1,0 \mathbf{a}$ & $245 \mathrm{aA}$ & $22 \mathrm{abA}$ & $4,3 \mathrm{bB}$ & $362 \mathrm{bB}$ & $243 a$ \\
\hline $\mathrm{CCO}-250 \mathrm{P}$ & 7,4 & $1,2 \mathrm{a}$ & $3,9 \mathrm{bA}$ & $4,6 \mathrm{a}$ & $2,3 \mathrm{~A}$ & $0,6 \mathbf{a}$ & $203 \mathrm{abA}$ & $19 \mathrm{bA}$ & $3,6 \mathrm{bB}$ & $270 \mathrm{cB}$ & $181 b$ \\
\hline SCO-125P & 7,1 & $0,9 a$ & $4,0 \mathrm{bB}$ & $6,7 \mathrm{~b}$ & $2,6 \mathrm{~A}$ & $1,2 \mathrm{a}$ & $178 \mathrm{bB}$ & $33 \mathrm{aA}$ & $4,3 \mathrm{bB}$ & $732 \mathrm{aA}$ & $268 a$ \\
\hline SCO-250P & 7,3 & $1,5 \mathrm{a}$ & $4,5 \mathrm{bB}$ & $5,2 \mathrm{a}$ & $2,3 \mathrm{~A}$ & $2,0 \mathrm{~b}$ & $186 \mathrm{bB}$ & $36 \mathrm{aA}$ & $7,0 \mathrm{aA}$ & $762 \mathrm{aAA}$ & $188 b$ \\
\hline \multicolumn{12}{|c|}{ caule+galho } \\
\hline$A B-250 P$ & 2,8 & 2,9 & 6,4 & $4,2 b$ & $0,7 b$ & 1,0 & $126 a$ & $24 b$ & $5,3 \mathrm{bA}$ & $229 \mathrm{bB}$ & $248 \mathrm{aB}$ \\
\hline $\mathrm{CCO}-250 \mathrm{P}$ & 2,9 & 2,9 & 6,0 & $5,1 a b$ & $0,8 b$ & 0,9 & $91 \mathrm{~b}$ & $31 b$ & $4,3 \mathrm{aA}$ & $203 \mathrm{bB}$ & $142 \mathrm{bA}$ \\
\hline SCO-125P & 2,6 & 2,7 & 8,2 & $6,3 \mathbf{a}$ & $1,3 \mathrm{ab}$ & 0,6 & $152 a$ & $43 a$ & $7,6 \mathrm{aB}$ & $348 \mathrm{aAB}$ & $223 \mathrm{aA}$ \\
\hline SCO-250P & 3,0 & 3,8 & 7,7 & $6,7 \mathrm{a}$ & $1,5 a$ & $\begin{array}{r}0,6 \\
\text { raiz }\end{array}$ & $117 a$ & $51 a$ & $8,6 \mathrm{aB}$ & $358 \mathrm{aAB}$ & $244 \mathrm{aB}$ \\
\hline $\mathrm{AB}-250 \mathrm{P}$ & $7,4 \mathrm{aA}$ & 1,5 & 3,8 & $1,7 \mathrm{bB}$ & $0,8 \mathrm{~b}$ & 1,7 & $12754 \mathrm{aB}$ & $227 \mathrm{aA}$ & $28 \mathrm{~A}$ & $112 \mathrm{aA}$ & $10784 \mathrm{aA}$ \\
\hline $\mathrm{CCO}-250 \mathrm{P}$ & $7,3 \mathrm{aA}$ & 2,1 & 3,3 & $1,7 \mathrm{bB}$ & $0,7 b$ & 1,5 & $12692 \mathrm{aA}$ & $167 \mathrm{bA}$ & $26 \mathrm{~A}$ & $103 \mathrm{aA}$ & $6116 \mathrm{bA}$ \\
\hline SCO-125P & $5,4 \mathrm{bB}$ & 1,1 & 4,5 & $3,3 \mathrm{aA}$ & $1,4 \mathrm{a}$ & 1,8 & $9268 \mathrm{bA}$ & $123 \mathrm{bB}$ & $21 \mathrm{~A}$ & $67 \mathrm{bA}$ & $6550 \mathrm{bA}$ \\
\hline SCO-250P & $6,9 \mathrm{aA}$ & 1,8 & 3,5 & $3,0 \mathrm{aA}$ & $1,7 \mathrm{a}$ & 2,4 & $7275 \mathrm{cB}$ & $153 \mathrm{bB}$ & $25 \mathrm{~A}$ & $67 \mathrm{bA}$ & $6568 \mathrm{bA}$ \\
\hline
\end{tabular}


Tabela 6 Composição química ${ }^{(1)}$ dos diferentes componentes das espécies de Pinus.

\begin{tabular}{|c|c|c|c|c|c|c|c|c|c|c|c|}
\hline Tratamento & $\mathbf{N}$ & $\mathbf{P}$ & $\mathbf{K}$ & $\mathrm{Ca}$ & Mg & $\mathbf{S}$ & Fe & $Z_{n}$ & $\mathrm{Cu}$ & Mn & Al \\
\hline & \multicolumn{11}{|c|}{$\begin{array}{c}\text { Pinus oocarpa } \\
\text { acículas }\end{array}$} \\
\hline $\mathrm{AB}-250 \mathrm{P}$ & 8,3 & 1,2 & 6,7 & 2,1 & 0,9 & 1,1 & $204 \mathrm{~A}$ & 24 & 5 & $302 a$ & 365 \\
\hline $\mathrm{CCO}-250 \mathrm{P}$ & 8,0 & 1,0 & 5,9 & 2,0 & 1,2 & 1,5 & $235 \mathrm{~A}$ & 19 & 5 & $69 b$ & 287 \\
\hline SCO-125P & 7,6 & 1,0 & 7,7 & 2,3 & 1,2 & 2,0 & $294 \mathrm{~A}$ & 23 & 4 & $385 a$ & 311 \\
\hline SCO-250P & 8,8 & 1,1 & 6,1 & 2,3 & 1,4 & 1,5 & $221 \mathrm{~A}$ & 23 & 5 & $315 a$ & 343 \\
\hline \multicolumn{12}{|c|}{ caule } \\
\hline $\mathrm{AB}-250 \mathrm{P}$ & 3,2 & 1,3 & 3,7 & 1,0 & 0,5 & 0,2 & 92 & 20 & 5 & $86 a$ & 236 \\
\hline $\mathrm{CCO}-250 \mathrm{P}$ & 2,9 & 1,2 & 3,5 & 1,1 & 0,7 & 0,3 & 70 & 18 & 5 & $25 b$ & 204 \\
\hline SCO-125P & 3,0 & 0,7 & 5,5 & 1,1 & 0,9 & 0,5 & 77 & 19 & 4 & $74 a$ & 189 \\
\hline \multicolumn{12}{|c|}{ Raiz } \\
\hline AB- & $6,6 \mathrm{~B}$ & 1,3 & 3,6 & $1,7 \mathrm{~b}$ & 0,8 & 1,2 & 5905 & $42 a$ & 15 & $64 \mathrm{bB}$ & $11295 \mathrm{a}$ \\
\hline $\mathrm{CCO}-250 \mathrm{P}$ & $6,2 \mathrm{~B}$ & 0,9 & 3,3 & $3,0 \mathrm{a}$ & 1,2 & 1,3 & 6379 & $23 b$ & 14 & $37 \mathrm{cA}$ & $7243 b$ \\
\hline SCO-125P & $6,0 \mathrm{~B}$ & 1,0 & 3,5 & $2,6 \mathrm{a}$ & 1,9 & 1,5 & 6300 & $52 \mathrm{a}$ & 16 & $69 \mathrm{bB}$ & $7270 \mathrm{~b}$ \\
\hline SCO-250P & $6,0 \mathrm{~B}$ & 0,8 & 4,4 & $2,8 \mathrm{a}$ & 0,8 & 1,6 & 5245 & $40 a$ & 14 & $91 \mathrm{aB}$ & $7294 b$ \\
\hline \multicolumn{12}{|c|}{ P. caribaea var. hondurensis } \\
\hline \multicolumn{12}{|c|}{ acículas } \\
\hline $\mathrm{AB}-250 \mathrm{P}$ & 8,2 & 1,1 & 5,8 & 2,1 & 1,3 & 1,3 & $150 \mathrm{~B}$ & 20 & 4 & $354 a$ & 305 \\
\hline $\mathrm{CCO}-250 \mathrm{P}$ & 8,2 & 1,1 & 5,8 & 2,2 & 1,3 & 1,3 & 150B & 20 & 4 & $72 b$ & 272 \\
\hline SCO-125P & 7,3 & 1,0 & 6,0 & 2,9 & 1,3 & 2,0 & 132B & 27 & 4 & $395 a$ & 367 \\
\hline SCO-250P & 8,9 & 1,1 & 7,2 & 2,3 & 1,3 & $\begin{array}{l}1,7 \\
\text { caule }\end{array}$ & 108B & 28 & 4 & $373 a$ & 360 \\
\hline $\mathrm{AB}-250 \mathrm{P}$ & 4,1 & 1,7 & 5,3 & 1,1 & 0,7 & 0,4 & $96 a$ & 24 & 5 & $97 a$ & 303 \\
\hline CCO-250P & 3,2 & 0,9 & 4,3 & 0,9 & 1,0 & 0,3 & $78 \mathrm{~b}$ & 16 & 4 & $18 b$ & 244 \\
\hline SCO-125P & 3,1 & 0,8 & 4,7 & 0,9 & 0,5 & 0,6 & $83 b$ & 21 & 4 & $82 a$ & 235 \\
\hline $\mathrm{SCO}-250 \mathrm{P}$ & 3,9 & 1,1 & 5,7 & 0,9 & 0,9 & $\begin{array}{l}0,6 \\
\text { raiz }\end{array}$ & $99 \mathrm{~b}$ & 24 & 4 & $94 a$ & 230 \\
\hline AB-250P & $8,0 \mathrm{~A}$ & 1,4 & 4,6 & $1,2 \mathrm{~b}$ & 0,6 & 1,5 & 5263 & $42 a$ & 15 & $103 \mathrm{aA}$ & $11159 a$ \\
\hline $\mathrm{CCO}-250 \mathrm{P}$ & $7,4 \mathrm{~A}$ & 1,0 & 3,0 & $2,7 a$ & 1,1 & 1,2 & 5944 & $22 b$ & 13 & $33 \mathrm{bA}$ & $7396 b$ \\
\hline SCO-125P & $7,7 \mathrm{~A}$ & 0,8 & 6,1 & $3,2 \mathrm{a}$ & 0,9 & 1,6 & 4231 & $41 a$ & 14 & $108 \mathrm{aA}$ & $7555 b$ \\
\hline SCO-250P & $8,2 \mathrm{~A}$ & 0,9 & 5,3 & $3,3 a$ & 0,9 & 1,9 & 4815 & $57 a$ & 17 & $163 \mathrm{aA}$ & $7517 \mathrm{~b}$ \\
\hline
\end{tabular}

As espécies de Pinus, aos 300 dias de idade, apresentaram maior teor de alumínio nas raízes e na parte aérea do que as espécies de Eucalyptus aos 210 dias de idade (Tabela 6).

A redução no teor de alumínio, em função da aplicação do sulfato (tratamentos SCO-250 e SCO-125), pode ser explicada em função da reação de precipitação do alumínio com o sulfato, comum quando o teor de alumínio trocável é alto (Raij et al., 1987). A movimentação do alumínio também pode ser dificultada, por meio da imobilização deste, em reações de neutralização, que ocorrem em função da liberação de 
hidroxilas com a adsorção de sulfato. Com relação a isso, deve-se considerar, de acordo com Raij (1989), que o gesso diminui os teores e a atividade de alumínio no solo, embora isso possa ser benéfico para o desenvolvimento do sistema radicular, não pode ser interpretado como uma redução de acidez ou de alumínio, tampouco a formação de $\mathrm{AlSO}_{4}$ deve ser considerada como neutralização de alumínio. Trata-se apenas de uma associação de íons que ocorre na solução do solo, ocorrendo cancelamento mútuo de cargas, mas não transferência de prótons.

Apesar das diferenças nos teores de sulfato no solo, as mudas de eucalipto e de pinus não apresentaram diferenças na absorção deste nutriente, exceto para $0 E$. urophylla que apresentou maior teor nas raízes no tratamento $\mathrm{AB}-250 \mathrm{P}$ (Tabelas 5 e 6). Os resultados evidenciam que o alumínio não interferiu na absorção deste nutriente, e que as espécies não apresentaram diferenças entre si quanto à translocação deste elemento. Segundo Raij et al. (1987), os cátions polivalentes, como o cálcio e o alumínio, estimulam a absorção de sulfato pelas células radiculares. Curtin \& Syers (1990), ao contrário, constatou que o alumínio interfere na absorção de íons como o sulfato, afetando, principalmente, o crescimento radicular, reduzindo o suprimento de energia para o transportador e aumentando a viscosidade do protoplasma das células das raízes.

Quanto ao nitrogênio, o E. grandis apresentou menor teor deste nutriente na raiz, quando comparada com as demais espécies de Eucalyptus (Tabela 5). Supõe-se que isso ocorreu em função de sua menor produção de matéria seca neste componente. $O E$. urophylla e o híbrido $E$. grandis $v$. E. urophylla apresentaram menores teores nas raízes nos tratamentos SCO-250 e SCO-125, respectivamente. As espécies de Pinus não apresentaram diferenças entre os tratamentos, nas raízes e na parte aérea (Tabela 6). $O P$. caribaea var. hondurensis apresentou maior teor de nitrogênio na raiz que o $P$. oocarpa. Não foram verificadas diferenças nos teores de nitrogênio na parte aérea entre estas espécies.

O híbrido $E$. grandis vs. E. urophylla e o E. urophylla não apresentaram diferenças no teor de cálcio e magnésio na raiz, entre os tratamentos $\mathrm{AB}-250 \mathrm{P}$ e CCO- 
250P, que resultaram em menores e maiores teores trocáveis destes nutrientes no solo, respectivamente (Tabela 5). Estas constatações devem estar associadas à maior proliferação de raízes finas observadas no tratamento $\mathrm{AB}-250 \mathrm{P}$, aumentando o potencial de absorção destes nutrientes. Este efeito não foi observado para o $E$. grandis, espécie que apresentou os menores teores destes nutrientes no tratamento $A B-250 P$, relativamente ao CCO-250P. Talvez devido ao efeito de diluição, pois em AB-250P, constatou-se maior matéria seca radicular. $\mathrm{O} E$. urophylla não apresentou diferenças entre os tratamentos. As espécies de Pinus apresentaram menor teor de cálcio nas raízes no tratamento $A B-250 P$. Entretanto não se verificaram diferenças na concentração deste nutriente na parte aérea, entre os tratamentos. O maior teor de cálcio na parte aérea das mudas, associado ao menor teor deste cátion nas raízes, é um indício que a planta é mais tolerante ao alumínio e menos exigente em cálcio ou é capaz de utilizá-lo eficientemente.

Os teores de magnésio e potássio nas raízes de eucalipto não diferiram entre si (Tabela 5). Quanto as diferenças verificadas nos teores destes nutrientes na parte aérea das mudas, entre os tratamentos, sugere-se que seja um efeito de diluição, haja vista que não houve diferença na produção de matéria seca neste compartimento.

$\mathrm{O} E$. grandis apresentou maior teor de fósforo nas raízes nos tratamentos com maiores teores de alumínio trocável no solo (Tabela 5). Não foram verificadas diferenças no teor de fósforo nas raízes do $E$. urophylla e do híbrido $E$. grandis vs. $E$. urophylla. No entanto, de modo geral, as espécies de Eucalyptus não apresentaram diferenças no teor do fósforo na parte aérea das mudas. Este resultado sugere uma possível adaptação destas espécies, uma vez que o padrão típico da distribuição de fósforo em plantas estressadas por alumínio, é o acúmulo nas raízes e diminuição em órgãos da parte aérea (Macklon \& Sim, 1992). Admitindo-se que os efeitos negativos do alumínio trocável sobre a absorção de fósforo foram pequenas, pode-se inferir que a tolerância a toxicidade de alumínio deve estar relacionada com o aumento na eficiência de absorção deste nutriente, na presença deste íon, por meio da ampliação da extensão de raízes finas, consequentemente, da densidade de raízes finas, além da habilidade das mesmas 
de absorver fósforo na presença de excesso de alumínio. As espécies de Pinus não apresentaram diferenças entre si, quanto ao teor de magnésio, de potássio e de fósforo (Tabela 6).

Semelhante ao observado para o alumínio, as concentrações de ferro, cobre e zinco nas raizes, proporcionalmente às quantidades disponíveis do solo, foram muito maiores do que as encontradas nos tecidos foliares de todas espécies (Tabelas 5 e 6). Provavelmente, grande parte destes elementos estão adsorvidos à CTC de raízes. Ao contrário, as maiores concentrações de manganês foram encontradas nos tecidos foliares, talvez devido a uma maior absorção deste nutriente ocasionada por uma menor afinidade pela CTC das raízes e pelo efeito competitivo dos demais cátions, permeando a passagem do manganês pelo espaço livre aparente. Este comportamento pode predispor espécies de Eucalyptus e Pinus a uma maior susceptibilidade à toxicidade por manganês do que por alumínio.

\subsection{Capacidade de troca de cátions (CTC) das raízes finas}

O híbrido $E$. grandis vs. E. urophylla apresentou menor CTC de raízes finas nos tratamentos SCO-250P, SCO-125P e CCO-250P, quando comparado com as demais espécies (Tabela 7). Neste último tratamento, o E. urophylla apresentou menor CTC, quando comparado com $E$. grandis. É conhecido que a CTC de raiz afeta a absorção de íons pelas plantas. Maior CTC de raízes, facilita a absorção de cátions di e polivalentes pelas plantas, devido ao deslocamento de cátions monovalentes na parede celular, enquanto que menor CTC facilita a absorção de cátions monovalentes e ânions. Em conseqüência, espécies que apresentam menor CTC $\left(100-300 \mathrm{mmol}_{\mathrm{c}} \mathrm{Kg}^{-1}\right)$ são mais tolerantes ao alumínio, e usa mais eficientemente $\mathrm{o}_{4}$, e também tendem a acumular $\mathrm{K}$; plantas com alta CTC (300-600 $\left.\mathrm{mmol}_{\mathrm{c}} \mathrm{Kg}^{-1}\right)$ tendem a acumular Ca e Mg (Blamey, 1990). À princípio, este comportamente aplica-se ao eucalipto no presente estudo, quanto à exigência nutricional desses nutrientes, considerando que espécies de Eucalyptus são menos exigentes em cálcio e magnésio. Outra hipótese a ser considerada é que a adsorção de aluminio na CTC de raiz em conjunto com a suposta exudação de 
pequenas quantidades de ácidos orgânicos, capazes de complexar alumínio, pode reduzir a quantidade de alumínio potencialmente disponível e absorvível (Godoy, 2000).

Tabela 7 Capacidade de troca de cátions de raizes finas $(<1 \mathrm{~mm})$ para as diferentes espécies e tratamentos ${ }^{(1)}$..

\begin{tabular}{|c|c|c|c|c|}
\hline \multirow[t]{2}{*}{ Espécie } & \multicolumn{4}{|c|}{ Capacidade de troca de cátions de raízes finas } \\
\hline & $\overline{\mathrm{AB}-250 \mathrm{P}}$ & CCO-250P & SCO-125P & SCO-250P \\
\hline & \multicolumn{4}{|c|}{$-\mathrm{mmol}_{\mathrm{c}} \mathrm{Kg}^{-1}$} \\
\hline E.grandis & 312 & $339 \mathrm{~A}$ & $351 \mathrm{~A}$ & $310 \mathrm{~A}$ \\
\hline E. urophylla & $320 \mathrm{a}$ & $282 \mathrm{bB}$ & $343 \mathrm{aA}$ & $317 \mathrm{aA}$ \\
\hline E.urophylla vs. E.grandis & $313 \mathrm{a}$ & $247 \mathrm{bC}$ & $275 \mathrm{bB}$ & $252 \mathrm{bB}$ \\
\hline média & 315 & 289 & 323 & 293 \\
\hline Pinus oocarpa & 390 & 369 & 394 & 356 \\
\hline$P$. caribaea var. hondurensis & 375 & 356 & 390 & 360 \\
\hline média & 383 & 363 & 392 & 358 \\
\hline
\end{tabular}

De acordo com Manlio (1998), a menor CTC de raiz eleva a absorção de $\mathrm{NH}_{4}$ resultando em extrusão de prótons, que abaixam o pH do meio (espaço livre aparente $\mathrm{e}$ solução do solo), podendo aumentar a solubilização de formas de fósforo precipitadas com alumínio e ferro. Além disso, segundo este pesquisador, a passagem de ânions através de microporos da parede celular até os sítios de absorção na plasmalema é dificultada pela repulsão das cargas negativas fixas. $\mathrm{O}$ alumínio pode neutralizar as cargas negativas fixas, facilitando o fluxo de fósforo. Nessa linha de raciocínio, supõese, que estes constituam possíveis mecanismos do eucalipto para elevar a absorção de fósforo. Estes mecanismos teriam evoluído, juntamente com a adaptação ecológica de várias espécies de Eucalyptus aos solos distróficos da Austrália, pobres em fósforo disponivel. Quanto aos micronutrientes, deve-se considerar que a extrusão de prótons, reduzindo o pH do meio, pode promover maior solubilização de micronutrientes, como o zinco, o ferro e o cobre. 
As espécies de Pinus não diferiram entre si, quanto a capacidade de troca de cátions de raiz (Tabela 7). Entretanto, apresentaram maior CTC de raízes, aos 300 dias de idade que o eucalipto aos 210 dias de idade. Provavelmente, os maiores teores de alumínio verificados nas raízes de Pinus esteja associado à maior CTC de raízes destas plantas, capazes de adsorver maiores quantidades de alumínio. Pela mesma razão, maiores teores foliares de alumínio foram verificadas nas espécies de Pinus. 


\section{CONCLUSÕES}

1- As espécies de Eucalyptus e de Pinus não apresentaram diferenças de crescimento em altura, diâmetro do colo e produção de matéria seca da parte aérea entre os diferentes níveis de saturação de alumínio e disponibilidade de nutrientes no solo.

2- As espécies de Eucalyptus e de Pinus apresentaram maior produção de matéria seca de raízes finas nos tratamentos que receberam menor dosagem de fósforo ou calagem.

3 - O E. grandis apresentou maior densidade de raízes do que o E. urophylla, e este maior do que o híbrido E. grandis vs. E. urophylla.

4 - Maior densidade de raízes finas foram encontradas nos tratamentos com menores teores de bases e maiores teores de alumínio no solo, para todas as espécies estudadas.

5 - Para todas as espécies de Eucalyptus e de Pinus, mais de 95\% das raízes finas pertenciam a classe de raiz $<1 \mathrm{~mm}$.

6 - A CTC de raiz das espécies de Pinus foi maior do que as de Eucalyptus, as quais apresentaram menor teor foliar de alumínio.

7- Os teores de alumínio nas raízes finas foram muito maiores do que as encontradas nos tecidos foliares. Nas espécies de Pinus as diferenças foram maiores. 


\section{REFERÊNCIAS BIBLIOGRÁFICAS}

ADAMS, F. Interactions of phosphorus with other elements in soils and in plants. In: KHASAWNEH, F., (Ed.). The role of phosphorus in agriculture. Madison: American Society of Agronomy, 1980. p . 655-680.

ADAMS, F. Crop response to lime in the Southern United States. 2. ed. In: ADAMS, F., (Ed.). Soil acidity and liming. Madison: American Society of Agronomy, 1984. p.211-265.

ANDREW, C. S.; VAN DER BERG, P. J. The influence of aluminum on phosphate sorption by whole plants and excised roots of some pasture legumes. Plant of Soil, v. 24, p. $351-49,1973$

AHONEN-JONNARTH, U.; HEES, P. Q. W. V.; LUNDSTROM, U. S. et al. Organic acids produced by mycorrhizal Pinus syvestris exposed to elevated aluminium and heavy metal concentrations. Phytochemistry, 2000. v.9, p. 557-567.

ALAM, S.M; ADAMS, W.A. Effects of aluminum on nutrient composition and yield of oats. Journal of Plant Nutrition, v. 1, p. 365-375, 1979.

BARROS, N.F.; NOVAIS, R.F.; NEVES, J.C.L. Fertilização e correção do solo para plantio de eucalipto. In: NOVAIS, R.F.; BARROS, N.F (Ed.) Relação solo eucalipto. Viçosa: Editora Folha de Viçosa, 1990. cap. 4, p. 127-186.

BALIGAR, V.C.; SCHAFFERT, R.E.; SANTOS, H.L. et al. Soil aluminium effects on uptake, influx, and transport of nutrients in sorghum genotypes. Plant of Soil, v. 50, p. $271-277,1993$. 
BASSIONI, N.H. On the mechanism of nitrate uptake by plant roots. II. Effect of the valence of the associated cation. Agrochimica, v. 17, p. 341-346, 1973.

BENNET, R.J.; BREEN, C.M.; FEY, M.V. The effects of aluminium on root cap function and root development in Zea mays L. Environment Botanical, v. 27, p. 91-104, 1987.

BERISH, C.W.; EWEL, J.J. Root development in simple and complex tropical succecional ecosystems. Plant and Soil, v. 10, p. 73-84, 1988.

BLAMEY, F.P.C.; ROBINSON, N.J.; ASHER, C.J. Interspecific differences in aluminum tolerance in relation to root cation-exchange capacity. Plant and Soil, v. 14, p.77-82, 1992.

BLAMEY, F.P.C. Role of root cation-exchange capacity in diferential aluminum tolerance of Lotus species. Journal of Plant Nutrition, v. 6, p. 729-744, 1990.

BRACCINI, M.C.L; MARTINEZ, H.E.P.; PEREIRA, P.R.G. et al. Tolerância de genótipos de cafeeiro ao alumínio em solução nutritiva. II. Teores de $\mathrm{P}, \mathrm{Ca}$ e $\mathrm{Al}$ e eficiência ao P e Ca. Revista Brasileira de Ciência do Solo, v.22, p.445-450, 1998.

BROWN, J.C.; AMBLER, J.E. Sites of Fe reduction, absorption and transport. Physiological Plant, v. 31, p. 221-224, 1974.

BUENO, N. Quantidade de alumínio no substrato afetando o desenvolvimento, a sintomatologia de toxicidade, a concentração e o acúmulo de macronutrientes em seringueira (Hevea ssp). Piracicaba, 1987. 92 p. Tese (Doutorado). - Escola Superior de Agricultura "Luiz de Queiroz", Universidade de São Paulo.

BUTZ, R.G. \& JACKSON, W.A. A mechanism for nitrate transport and reduction. Phytochemistry, v. 16, p. 409-417, 1977.

CAMBRAIA, J.; LEMOS FILHO, J.P.; ESTEVÃO, M.M; et al. Efeito do alumínio sobre os teores de $\mathrm{Mg}, \mathrm{Fe}, \mathrm{Mn}, \mathrm{Zn}$ e $\mathrm{Cu}$ em sorgo. Revista Ceres, v.11, p. 45-54, 1983. 
CAMARGO, C.E.O. A concentração de fósforo na tolerância de cultivares de trigo à toxicidade de alumínio em soluções nutritivas. Bragantia, v.44, p. 49-64, 1985.

CAMARGO, O.A.; FURLANI, P.R. Alumínio no solo: concentração, especiação e efeito no desenvolvimento radicular. In: SIMPÓSIO AVANÇADO DE SOLOS E NUTRIÇÃO DE PLANTAS, 3; Piracicaba, 1989. Anais. Piracicaba: ESALQ, 1989. p. 45-69.

CARVALHO, S. S. Avaliações de duas populações de milho para a tolerância ao alumínio. Bragantia, v. 2, p. 40-60, 1994.

COSTA, M. E. Efeitos do alumínio, nitrato e amônio sobre a nutrição nitrogenada em Eucalyptus grandis Hill (Maiden). Viçosa, 1986. 50p. Dissertação (M. S) Universidade Federal de Viçosa.

CURTIN, D.; SYERS, J.K. Mechanism of sulphate adsorption by two tropical soils. Journal of Plant Nutrition, v. 41, p. 295-304, 1990.

CROOKE, W..M. The measurement of the cation-exchange capacity plant roots. Plant and Soil, v. 21, p. 43-49, 1964.

EMBRAPA, Serviço Nacional de levantamento e Conservação de Solos. Manual de métodos de análise de solo. Rio de Janeiro, 1979. 89p.

FOY, C.D. Soil chemical factors limiting plant root growth.. In: HATFIEL, J.L.; STEWART, B.A. Limitations to plant root growth. New York: Springer-Veilag, 1992. p. 97-149.

FOY, C.D. Plant adaptation to acid, aluminum-toxic soils. Communications in Soil Science and Plant Analysis, v. 9, p. 959-987. 1988.

FOY, C.D. Physiological effects of hydrogen, aluminum, and manganese toxicities in acid soil. In: ADAMS, F., (Ed.). Soil Science Society American. Madison, 1984, p.57-97. 
FOY, C.D. Effects of aluminum on plant growth. In: CARSON, E.W.(Ed.). The plant root and it environment. Charlottesville: University Press of Virginia, 1974. p. 601-642.

FOY, C.D. Effect of aluminum on uptake and metabolism of phosphorus by barley seedling. Plant Physiology, v. 41, p.165-172, 1966.

FOY, C.D.; ARMINGER, W.H.; BRIGGLE, L.W. et al. Differential aluminum tolerance of wheat and barley varieties associated with. Plant induced $\mathrm{pH}$ changes around theirs roots. Soil Science Society of America Proceedings, v.29, p. 64 -67, 1965.

FURLANI, P.R. Efeitos fisiológicos do alumínio em plantas. In: SIMPÓSIO AVANÇADO EM SOlOS E NUTRIÇÃO DE PLANTAS, 2., Piracicaba, 1989. Anais. Piracicaba, 1989, p.73-90.

FURTINI NETO, A.E.; BARROS, N.F.; GODOY, M.F. et al. Eficiência nutricional de mudas de Eucalyptus em relação a fósforo. Revista Árvore, v. 1, p. 17-28, 1996.

GONÇALVES, J. L. M.; MELLOJ. L. O sistema radicular das árvores. In: GONÇALVES, J. L. M; BENEDETTI, V. (Eds.) Nutrição e Fertilização florestal. Piracicaba: IPEF, 2000. cap. 8, p. 219-269.

GONÇALVES, J.L.M. Características do sistema radicular de absorção do Eucalyptus grandis Sob diferentes condições edáficas. Piracicaba, 1994. 84p. Tese (LivreDocência) - Escola Superior de Agricultura "Luiz de Queiroz", Universidade de São Paulo.

GONÇALVES, J.F.C.; CAMBRAIA, J. Efeito do alumínio sobre a atividade de enzimas do metabolismo dos ácidos orgânicos Revista Brasileira de Fisiologia Vegetal, v.11, p.16-22, 1999.

GODOY, A. D., Aluminium and nutrient strategies of cerrado trees. Communications in Soil Science and Plant Analysis, v. 25, p.1091-1103, 2000. 
GRIME, J.P.; HODGSON, J.G. An investigation of the ecological significance of lime chlorosis by means of large scale comparative experiments. In: RORISON, I.H.(Ed.) Ecological aspects of the mineral nutrition of plants. Oxford: Blackwell Scientific, 1969. cap. 2, p. 67-69.

HAMPP, $\mathrm{R}$; SCHNABL, $\mathrm{H}$. Effect of aluminum ions on ${ }^{14} \mathrm{CO}_{2}$ - fixation and menbrane system of isolated spinach chloroplasts. Communications in Soil and Plant Analysis, v. 6, p.300-306. 1975.

HARIDASAN, M. Performance of Miconia albicans Triana, na aluminium accumulating species na acidic and calareous soils. Communications in Soil and Plant Analysis, v.9. p. $1091-1103.1988$

HAUG, A. Molecular aspects of aluminum toxicity. Plant Science, v. 1, p. 165-186, 1984.

HECHT-BUCHHOLZ C.; FOY, C. D., Effects of aluminium toxicity on root morphology of barley. Plant and Soil, v. 8, p.93-95, 1981.

HUANG, J.; BACHELARD, E. P. Effects of aluminium on cation uptake in seedlings of Eucalyptus mannifera and Pinus radiata. Plant and soil, v.14, p. 121-127, 1993.

HUE, N. V.; GRADDOCK, G.R.; ADAMS, F. Effect of organic acids on aluminumorganic mather complexes. Soil Science Society of America Journal, v.50, p. 2834, 1986.

JACKSON, W.A. Physiological effects of soil acidity. In: PEARSON, R.W.; ADAMS, F. (Ed.) Soil acidity and liming. Madison: American Society of Agronomy, 1977. p.43-124.

JORGE, L. A. C.; RESENDE, P. C. S.; POSAADAS DURAND, A. et al. Comparação de técnicas de análises de imagens digitais na determinação do comprimento de raízes. In: REUNIÃO BRASILEIRA DE MANEJO E CONSERVAÇÃO DO SOLO E DA ÁGUA. 10, Londrina, 1993. Resumos. Londrina, 1993. p.314-315. 
LINDSAY, W. L.; NORVELL, W. A. Development of a DPTA soil test for zinc, iron, manganese and copper. Soil Science Society of America Journal, v. 42, p 421-428, 1978.

LYFORD, W. H. Rhizography of non-wood roots of trees in the forest floor. In: TORREY, J.; CLARKSON, D. T.(Ed.). The development and function of roots. Charlottesville, University Press of Virginia, 1975. cap. 4, p. 179-196.

MACKLON, A.E.S.; SIM, A. Modifying effects of a nom-toxic level of aluminium on phosphate fluxes and compartmentation in root cortex cells of intact ryegrass seedlings. Journal Botanical, v.43, p.148-149, 1992.

MALAVOLTA, E; VELOSO, C. A. C.; TAKASHI, M. Alumínio e a absorção de cálcio por mudas de pimenta do reino. Scientia Agricola, v. 47, p.1-9, 2000.

MALAVOLTA, E.; VITTI, G.C.; OLIVEIRA, S.A. Avaliação do estado de nutricional das plantas: Princípios e aplicações. Piracicaba: Potafós,1989. 201p.

MALAVOLTA, E. Elementos da nutrição mineral de plantas. São Paulo: Editora Agronômica Ceres, 1980. 251p.

MALAVOLTA, E.; VITTI, G.C.; OLIVEIRA, S.A. Avaliação do estado nutricional das plantas: Princípios e aplicações. Piracicaba: Potafós,1997. 304p.

MACHADO, S. A. Curvas de índice de sítios para plantações de Pinus taeda L. na região central do Paraná. Floresta, v. 11, p.4-18, 1988.

MARSCHNER, H. Mineral nutrition of higher plants. Institute of Plant Nutrition; University of Hohenheim. 1986. 674p.

MANLIO, A.E.S. Above and bellow-ground organic matter and root-shoot ration in a cerrado in central Brasil. Journal Botanical. v.65, p.148-190, 1998.

MENGEL, K.; KIRKBY, E.A. Principles of plant nutrition. Institute of Plant Nutrition; University of Hohenheim. 1982. 655p.

MINOTTI, P.L.; WILLIAMS, D.C.; JACKSON, W.A. Nitrate uptake by wheat as influenced by ammonium and other cations. Crop Science, v. 9, p. 9-14, 1969. 
MULLETE, K.J.; HANNON, J. N. Insoluble phosphorus usage by eucalyptus. Plant and Soil, v. 41, p. 199-205, 1974.

NAMBIAR, E.K.S. Root development and configuration in intensively managed radiata pine plantations South Australia. Plant and Soil, v. 71, p. 37-47, 1983.

NAMBIAR, E.K.S.; COTTERILL, P. P.; BOWER, G. D. Genetic diferences in root regeneration of radiata pine. Jounal of Experimental Botany, v. 33, p. 170- 177, 1982.

NEVES, J.C.L.; NOVAIS, R.F.; BARROS, N.F. Efeito do alumínio em solução nutritiva no crescimento e absorção de nutrientes por Eucalyptus spp. Revista Árvore, v.1, p.1-16, 1982.

NOVAIS, R.F.; BARROS, N.F.; NEVES, J.C.L. Nutrição mineral do eucalipto. In: NOVAIS, R.F.; BARROS, N.F (Ed.). Relação solo - eucalipto. Viçosa: Editora Folha de Viçosa, 1990. cap. 2, p. 25-98.

NOVAIS, R.F.; GOMES, J.M.; NASCIMENTO FILHO, M.B. et al. Calagem e adubação mineral na produção de mudas de eucalipto (Eucalyptus grandis W. Hill ex. Maiden): Efeitos da calagem, do superfosfato simples e de um fertilizante NPK. Revista Árvore, v.4, p.22-111, 1980.

PAIVA, E. Genética e bioquimica da tolerância ao alumínio, Revista Brasileira de Fisiologia Vegetal, v.11, p.7-11, 1999.

RAIJ, B.V. Melhoria do ambiente radicular do subsolo. In: SIMPÓSIO AVANÇADO DE SOLOS E NUTRIÇÃO DE PLANTAS, 2.; Piracicaba, 1989. Anais. Piracicaba: ESALQ/USP, 1989. p.117-148.

RAIJ, B. V.; QUAGGIO, J. A.; CANTARELLA, H. et al. Análise química do solo para fins de fertilidade. Campinas: Fundação Cargill, 1987. 170 p.

REIS, M. F.G.; BARROS, N.F.; KIMMINS, J.P. Acúmulo de nutrientes em uma seqüência de idade de Eucalyptus grandis W. Hill (ex-Maiden) plantado no serrado, 
em duas áreas com diferentes produtividades, em Minas Gerais. Revista Árvore, v.1, p.1-15, 1987.

REIS, M. F.G \& KIMMINS, J.P. Importância do sistema radicular no crescimento inicial de brotos de Eucalyptus spp. Revista Árvore, v.2, p.196-201, 1986.

REISSMANN, B. C; WISNEWSKI, C. Aspectos nutricionais de plantos de pinus. In: GONÇALVES, J. L. M; Benedetti, V. (Eds.) Nutrição e fertilização florestal. Piracicaba: IPEF, 2000. cap. 5, p. 352-368.

ROY, K.A.; SHARMA, A.; TALUKDER, G. Some aspects of aluminum toxicity in plants. The Botany Review, v. 5, 1988, p.145-78.

SANCHES, P. A.; SALINAS, J.G. Low imput technology for managing oxisols and ultisols in tropical America. Advances in Agronomy, v.5, p. 279 - 406, 1981

SARRUGE, J.R. \& HAAG, H.P. Análise química em plantas. Piracicaba, ESALQ, 1974. $56 \mathrm{p}$.

SCHOTTELNDREIER, M.; GRERUP-FAKENGREN, U. Plant induced alternation in the rhizosphere and the utilisation of soil hetergeneity. Plant and Soil, v. 5, p.297309, 1999.

TAYLOR, G.J. The physiology of aluminum tolerance in the tropics. Communications in Soil and Plant Analysis, v. 19, p. 1179-1194. 1988.

TAN, K.; KELTJENS, W.G. Analysis of acid-soil stress in dorghum genotypes with emphasis on aluminium and magnesium interactions. Plant and Soil, v.1, p.147-150, 1995.

VALE, F.R. Efeito do alumínio sobre a cinética de absorção de nitrato, amônio e fosfato em milho (Zea may, L.) e em clone de Eucalipto (Eucalyptus alba). Viçosa, 1982. 71p. Dissertação (M.S.) - Universidade Federal de Viçosa.

VERSTRAETEN S.V.; OTIZA P.I., Effects of $\mathrm{Al}^{+3}$ and related metals on menbrane phase state and hydration: Correlation whith lipid oxidation. Archives of Biophysics, v.37, p. 340-346, 2000. 
WESTMAN, W.E.; ROGERS, R.W., Nutrient stocks in a subtropical eucalypt forest, north Stradbroke Island. Journal Botanical, v.25, p.171-191, 1977. 